\title{
REVISED The unfolded protein response and its potential role in
}

\section{Huntington's disease elucidated by a systems biology}

\section{approach [version 2; peer review: 2 approved]}

\author{
Ravi Kiran Reddy Kalathur1, Joaquin Giner-Lamia1, Susana Machado1, \\ Tania Barata1, Kameshwar R S Ayasolla1, Matthias E. Futschik ${ }^{1,2}$ \\ ${ }^{1}$ Centre for Biomedical Research, University of Algarve, Faro, 8005-139, Portugal \\ ${ }^{2}$ Centre of Marine Sciences, University of Algarve, Faro, 8005-139, Portugal
}

V2 First published: 01 May 2015, 4:103

https://doi.org/10.12688/f1000research.6358.1

Latest published: 02 Mar 2016, 4:103

https://doi.org/10.12688/f1000research.6358.2

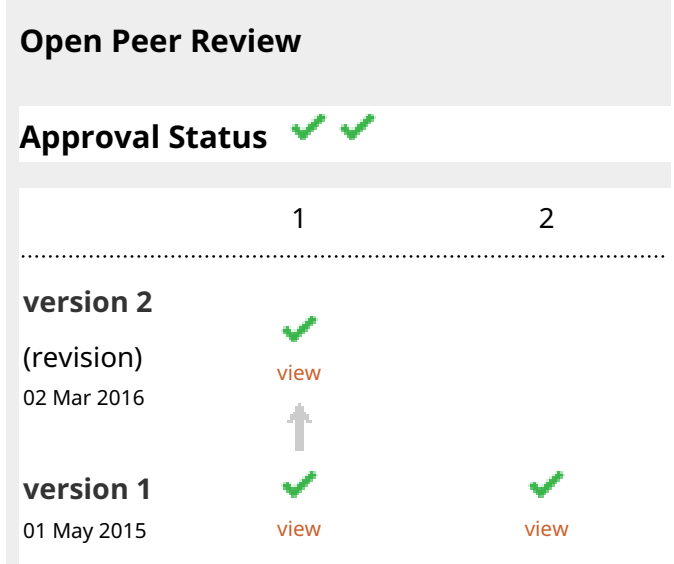

1. Scott Zeitlin, University of Virginia,

Charlottesville, USA

2. Stefan Taubert (iD), University of British

Columbia, Vancouver, Canada

Any reports and responses or comments on the article can be found at the end of the article. 
interactive analysis of UPR-associated gene expression across various HD models.

\section{Keywords}

Unfolded protein response (UPR), Huntington's disease, Apoptosis, UPR interactome, HTT interactome

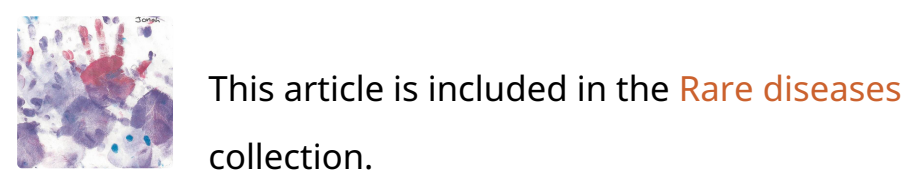

Corresponding author: Matthias E. Futschik (mfutschik@ualg.pt)
Competing interests: No competing interests were disclosed.

Grant information: The work presented was supported by CHDI Foundation (A-2666) and by the Portuguese Fundação para a Ciência e a Tecnologia (SFRH/BPD/70718/2010 to RKK and IF/00881/2013 to MEF).

The funders had no role in study design, data collection and analysis, decision to publish, or preparation of the manuscript.

Copyright: ( $) 2016$ Kalathur RKR et al. This is an open access article distributed under the terms of the Creative Commons Attribution License, which permits unrestricted use, distribution, and reproduction in any medium, provided the original work is properly cited. Data associated with the article are available under the terms of the Creative Commons Zero "No rights reserved" data waiver (CC0 1.0 Public domain dedication).

How to cite this article: Kalathur RKR, Giner-Lamia J, Machado $S$ et al. The unfolded protein response and its potential role in Huntington's disease elucidated by a systems biology approach [version 2; peer review: 2 approved] F1000Research 2016, 4:103 https://doi.org/10.12688/f1000research.6358.2

First published: 01 May 2015, 4:103 https://doi.org/10.12688/f1000research.6358.1 


\section{REVISED Amendments from Version 1}

In the updated version of the article, we included the results of additional analyses of differentially regulated UPR genes that were defined using less stringent requirements. This led to the identification of enlarged set of 53 proteins that link UPR and HD. Moreover, we distinguished between direct and indirect interactors of HTT, and supply these in the Supplementary materials. We also carried out analyses of additional RNA-Seq data for CAG repeat length-dependent gene expression and report the results showing that UPR gene expression tend to be strongly correlated with CAG repeat length. Finally, we briefly describe the newly implemented web-tool (UPR-HD freely accessible at http://uprhd.sysbiolab.eu) for visualisation and inspection of UPR-related gene expression in HD models and patients.

See referee reports
ER stress can mediate toxicity and eventually lead to apoptosis through activation of JNK, ASK1 and caspase-12. Figure 1 depicts the different mechanisms and outcomes of UPR activation.

\section{UPR and HD}

ER stress and UPR have been indicated for a variety of neurodegenerative disorders, where protein misfolding plays a significant role $^{18-20}$. For HD, finding a direct connection appears to be an enigma at first glance, since HTT is commonly thought to be located in the cystosol or eventually in the nucleus ${ }^{21}$, but not within the ER lumen. Thus, its misfolding should not trigger UPR. However, several proposals have been put forward to describe how mutant HTT (mHTT) can induce an ER stress response ${ }^{12}$. For instance, experimental evidence from HD cell models suggests that cytosolic mHTT fragments strongly impair ER-associated protein degradation (ERAD), since mHTT entraps ERAD proteins ${ }^{22}$. This impairs the proper

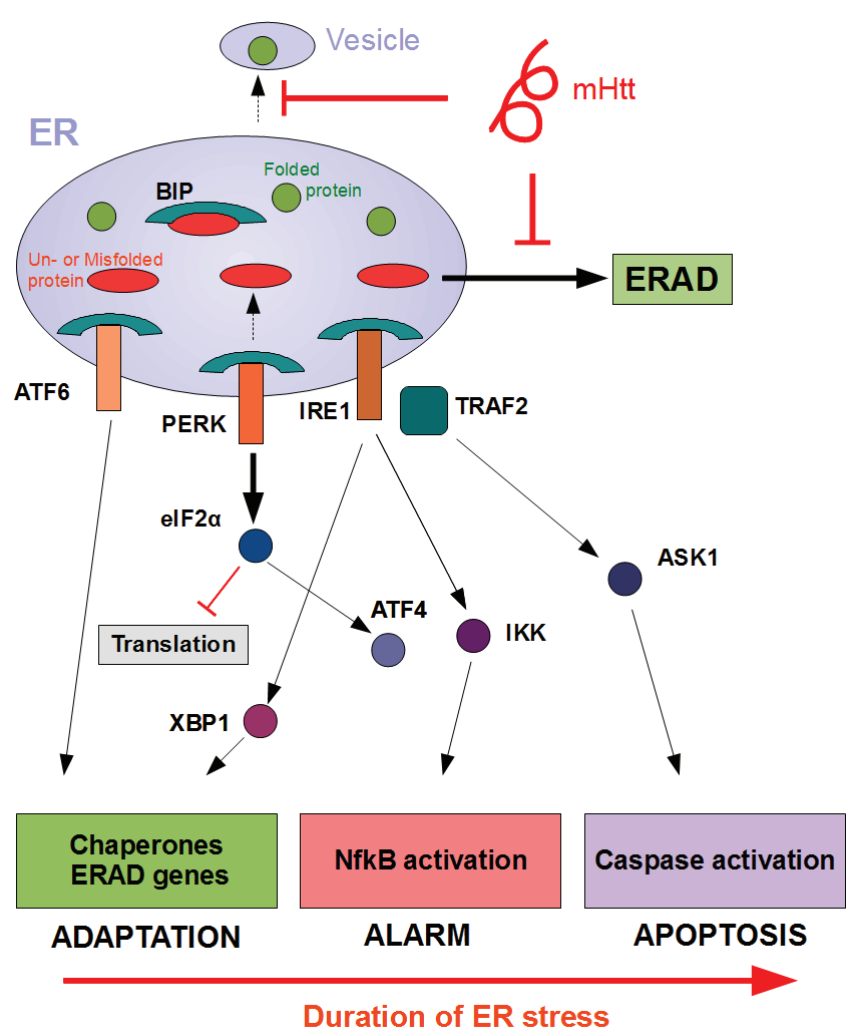

Figure 1. Phases of UPR activation and putative triggering of ER stress by mHTT. One explanation for how UPR sensors IRE1, PERK and ATF6 are activated is through detachment of chaperone $\mathrm{BiP}$ in the presence of excess un- or misfolded protein. This leads subsequently to the execution of a series of molecular processes with different effector functions ${ }^{17}$. As an adaptive response, the UPR up-regulates transcription of chaperones, temporarily attenuates new translation, and activates protein degradation via the proteasome. Persistent levels of ER stress, however, may trigger inflammatory pathways as an alarm signal in addition to caspase activation, leading ultimately to the induction of apoptosis. Mutant Huntingtin (mHTT) might provoke ER stress through interference with different processes such as vesicular transport or ER-associated degradation (ERAD) resulting in accumulation of (misfolded) protein in the ER. re-establishing homeostasis by increasing the overall folding capacity. Although the primary role of UPR is an adaptive one, persistent 
protein catabolism, causing a potential accumulation of misfolded proteins in the ER, effectively interfering with its correct functioning. Another alternative route towards ER stress in HD could be the perturbation of vesicular trafficking by mHTT resulting in a general protein overload in the ER or the disturbance of ER calcium homeostasis leading to a decreased folding capacity ${ }^{12}$. Moreover, HTT may even be an integral part of the ER stress response, as a reversible association of HTT via its highly conserved N-terminal domain with the ER membrane was observed ${ }^{23}$. Under stress conditions, HTT is released and translocates to the nucleus, where it might impact on gene expression. Nuclear export and the subsequent re-attachment of HTT to the ER then terminate this stress response. It was suggested that such a potential control mechanism is disturbed through the nuclear accumulation of mHTT resulting in a perturbed $\mathrm{ER}$ in $\mathrm{HD}^{24}$.

Although various lines of investigations have shown a potential role for UPR in the pathogenesis of HD, it remains difficult to assess its overall influence, given that the animal models and cell lines used in each individual study display great variability and distinct characteristics. Furthermore, most studies addressing the connection between UPR and HD focus on a small set of genes and proteins ${ }^{25,26}$. As the UPR presents a potentially important process in HD progression and a novel therapeutic target, we aimed to complement these previous studies with systematic and comprehensive bioinformatic analyses. Accordingly, using a systems biology approach, we gathered all available data and focused on detecting the activation of UPR during HD, and also on elucidating the potential connection between UPR and apoptosis in HD.

First, we assembled different sets of genes associated with the UPR and examined whether the included genes show differential expression in HD models or patients, when compared to controls. Next, we examined the promoter regions of upregulated UPR genes and detected significant enrichment of characteristic stress response elements. Additionally, we performed functional enrichment analysis on differentially expressed genes and found major biological processes implicated in UPR to be significantly over-represented. Furthermore, we assembled the UPR interactome and identified common proteins involved with apoptotic processes and interacting with HTT, since those could provide crucial links between apoptosis and HD.

\section{Materials and methods}

Derivation of gene sets for UPR, apoptosis and HD

Since the UPR is a complex process, it is challenging to define a unique set of associated genes. Accordingly, we compiled three alternative gene sets that are either directly or indirectly involved in UPR, gathered from distinct sources. The first termed, UPRKEGG-GO ( $n=265)$, was derived from Gene Ontology ${ }^{27}$ (http:// geneontology.org/page/go-database) (RRID:nif-0000-20935) as well as Reactome (http://www.reactome.org/) (RRID:nif-0000-03390) ${ }^{28}$ and KEGG Pathway database ${ }^{29}$ (http://www.genome.jp/kegg/ pathway.html) (RRID:nlx_31015) databases indicated in Table 1. The second, referred to as UPR-Interactions $(n=281)$, was generated by assembling molecular interactions of UPR components ATF6, ATF4, DDIT3, EIFAK3, ERNI and XBP1 using UniHI ${ }^{30}$ (http://www.unihi.org/) (RRID:nif-0000-03609) and HDNetDB databases (http://hdnetdb.sysbiolab.eu). The third gene set, labelled UPR-Literature $(n=2048)$ was compiled from published experimental studies ${ }^{31-34}$ performed in yeast and human cells using high-throughput techniques such as yeast two-hybrid, microarrays and ribosome profiling coupled with next generation sequencing, as well as from text-mining of the GeneCards database ${ }^{35}$ (http://www. genecards.org) (RRID:nif-0000-02879) (Table 1).

In order to examine the genes involved in the cross-talk between UPR and apoptosis, we derived a list of genes that are either directly or indirectly involved in apoptosis from several different sources, namely the Gene Ontology database (GO:0006915; Apoptotic process; $n=431$ ), KEGG pathway (hsa04210; Apoptosis; $\mathrm{n}=88$ ), Reactome pathway database (REACT_578.8; Apoptosis; $\mathrm{n}=148$; http://www.reactome.org/) (RRID:nif-0000-03390) and literature reviews $(n=85)^{36-40}$. All genes included were annotated to be involved in the induction of apoptosis, anti-apoptosis, regulation of apoptosis or were caspases (including both activators and inhibitors).

For establishing putative links to HD, we additionally put together two other gene sets:

(i) HD Therapeutic Targets (HDTT) comprising 1033 genes. This set includes genes which were annotated by the curators of the HD Research CrossRoads database as being associated with HD based on experimental evidence, making them potential therapeutic targets. A detailed description of this gene set is provided elsewhere by Kalathur et al. ${ }^{41}$. The list of HDTT can be accessed at http://hdtt.sysbiolab.eu/.

(ii) HTT interactors (HTT-int) including 1015 genes whose proteins have been shown to interact, or to be physically associated with HTT based on a diverse range of experiments. The large number of interactors can be explained through the inclusion of high-throughput affinity purification experiments, which frequently results in the addition of indirect interactions (e.g. within complexes). This set of interactors was obtained from the HDNetDB database (http://hdnetdb.sysbiolab.eu) and can be found in Supplementary data file 8. The annotation available in HDNetDB was used to distinguish direct and indirect interactions. In total, 234 proteins were registered as direct interactors.

\section{Collection and processing of HD gene expression data}

All HD gene expression data used for this study were downloaded from the Gene Expression Omnibus (GEO) database ${ }^{42}$ (http://www. ncbi.nlm.nih.gov/geo/) (RRID:nif-0000-00142). These data include gene expression from human brain and blood samples, human iPSCs, mouse, rat and yeast HD models, as well as murine cell lines (Table 2). All expression data sets were pre-processed using RMA (Robust Multi-array Average) implemented in R (available at http://www.r-project.org/) (RRID:nif-0000-10474) and analysed using several Bioconductor packages ${ }^{43,44}$ (RRID:nif-0000-10445). To enable the comparison across organisms, we mapped genes from mouse, rat, worm and yeast to orthologous human genes using HGNC Comparison of Orthology Predictions (HCOP) search 
Table 1. Data sources used to compile UPR gene sets.

\begin{tabular}{|c|c|c|c|c|c|}
\hline Gene set & \multicolumn{3}{|l|}{ Sub-classification } & $\begin{array}{l}\text { Number of } \\
\text { genes }\end{array}$ & $\begin{array}{c}\text { Total number of } \\
\text { unique genes }\end{array}$ \\
\hline \multirow{7}{*}{ UPR-KEGG-GO } & \multicolumn{3}{|l|}{ Pathway } & & \multirow{7}{*}{265} \\
\hline & \multicolumn{3}{|c|}{ KEGG:04141: Protein processing in ER } & 165 & \\
\hline & \multicolumn{3}{|c|}{ REACTOME: Unfolded protein response } & 79 & \\
\hline & \multicolumn{3}{|l|}{ Gene ontology } & & \\
\hline & \multicolumn{3}{|c|}{ GO:003043: ER-associated ubiquitin-dependent protein catabolic process } & 38 & \\
\hline & \multicolumn{3}{|c|}{ GO:0030968: endoplasmic reticulum unfolded protein response } & 89 & \\
\hline & \multicolumn{3}{|c|}{ GO:0034976: response to endoplasmic reticulum stress } & 142 & \\
\hline \multirow{7}{*}{ UPR-interactions } & \multicolumn{3}{|c|}{ Interactions } & & \\
\hline & \multicolumn{3}{|l|}{ ATF4 } & 92 & \\
\hline & \multicolumn{3}{|l|}{ ATF6 } & 34 & \\
\hline & \multicolumn{3}{|l|}{ DDIT3 } & 73 & 281 \\
\hline & \multicolumn{3}{|l|}{ EIF2AK3 } & 13 & \\
\hline & \multicolumn{3}{|l|}{ ERN1 } & 37 & \\
\hline & \multicolumn{3}{|l|}{ XBP1 } & 111 & \\
\hline \multirow{9}{*}{ UPR-Literature } & \multicolumn{3}{|c|}{ Publications (High through-put experiments) } & 1675 & \multirow{9}{*}{2048} \\
\hline & Study & Species & Method & & \\
\hline & Labunskyy VM et al. ${ }^{31}$ & Yeast & Ribosome profiling coupled with NGS & 189 & \\
\hline & Travers KJ et al. ${ }^{32}$ & Yeast & DNA microarray & 745 & \\
\hline & Jonikas MC et al. ${ }^{33}$ & Yeast & $\begin{array}{l}\text { Synthetic genetic array methodology \& } \\
\text { High-throughput flow cytometry }\end{array}$ & 1262 & \\
\hline & Christianson JC et al. ${ }^{34}$ & Human & $\begin{array}{l}\text { Affinity purification, LC-MS/MS, } \\
\text { High-throughput Y2H }\end{array}$ & 75 & \\
\hline & \multicolumn{3}{|l|}{ GeneCards } & & \\
\hline & \multicolumn{3}{|c|}{ GeneCards: ER-Stress } & 275 & \\
\hline & \multicolumn{3}{|c|}{ GeneCards: Unfolded Protein Response } & 325 & \\
\hline
\end{tabular}

\begin{tabular}{|c|c|c|c|}
\hline GEO ID & Sample & Organism & Pubmed id \\
\hline GSE3790 & $\mathrm{HD}(\mathrm{CN})$ vs Control & Human & 16467349 \\
\hline GSE24250 & HD vs Control (blood) & Human & 21969577 \\
\hline GSE37547 & HD-iPSC vs corrected HD iPSC & Human & 22748967 \\
\hline GSE3621 & R6/1-18w, 22w, 27w vs WT & Mouse & 17696994 \\
\hline GSE9803 & R6/2-12W vs WT & Mouse & 17519223 \\
\hline GSE10202 & CHL2-22m vs WT & Mouse & 17519223 \\
\hline GSE9330 & Ctip2-KO vs WT & Mouse & 18199763 \\
\hline GSE18551 & YAC128-12, 24m vs WT & Mouse & 20089533 \\
\hline GSE3583 & HdhQ111 vs WT & Mouse & 17708681 \\
\hline GSE9760 & mESC (CAG150)-d4, d6 vs WT & Mouse & NA \\
\hline GSE12481 & Neuronal-culture $82 \mathrm{Q}$ vs CT & Rat & 18815258 \\
\hline GSE18644 & $H t t 103 Q$ vs Htt25Q & Yeast & 21044956 \\
\hline
\end{tabular}


tool (available online at http://www.genenames.org/cgi-bin/hcop), which is based on integrated data from HUGO Gene Nomenclature Committee (HGNC) ${ }^{45}$ (RRID:nif-0000-02955).

Additionally, we evaluated an unpublished expression dataset (available at http://chdifoundation.org/datasets) generated by the CHDI Foundation. It comprises RNA-Seq measurements of striatum, cortex and liver tissue taken from 6 month old heterozygote mice with CAG lengths of 20, 80, 92, 111, 140, and 175 . The availability of data for distinct repeat lengths enables the examination whether expression changes are dependent on the length of the HTT polyglutamine tract. Spearman correlation between CAG number and gene expression measured as fragments per kilobase of exon per million reads mapped (FPKM) was calculated for each gene. False discovery rates (fdr) for positive and negative correlation were estimated by comparing the observed correlation coefficients with the distribution of correlation coefficients obtained for permutated data. For the latter, the CAG numbers of samples were permutated independently and repeatedly for each gene and subsequently correlated with the FPKM. Results are only reported for striatum, as preliminary analyses indicated only weak correlation for cortex and liver. The significance of overrepresentation of UPR genes among significantly correlated genes ( $\mathrm{fdr}<0.01)$ was assessed using the Fisher's exact test.

\section{Identification of differential expression using Gene Set Enrichment Analysis (GSEA)}

We performed gene set enrichment analysis (GSEA) ${ }^{46}$ (RRID:nif0000-30629) comparing HD-associated expression to wild type or control data to identify differentially expressed genes. As input, we used the above-mentioned UPR gene sets and HD gene expression data. UPR genes were identified as significant when the enrichment score (ES) corresponded to a $f d r \leq 0.05$ in HD gene expression data sets. For further analysis, we used only the genes present in the 'UPR core enrichment' gene sets. Those genes belonged to the leadingedge subsets and contributed the most to the enrichment scores, and are the most differentially expressed among the UPR genes. To visualize these results, we generated Venn diagrams using jvenn ${ }^{47}$, to display the common genes across alternative comparisons.

\section{Identification of stress response elements in the promoter regions}

In order to verify the presence of unfolded protein response element (UPRE) and ER stress response elements (ERSE I and II) ${ }^{48}$ in the upstream regions $(-1000 \mathrm{bp}$ to $+500 \mathrm{bp})$ of UPR genes upregulated in HD, we downloaded all the human promoter regions, $(n=23322)$ available in the eukaryotic promoter database (EDP; http://epd.

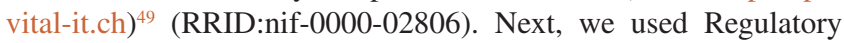
Sequence Analysis Tools (RSAT) ${ }^{50}$ to map these elements in the promoters and computed the enrichment of these stress elements in promoters of upregulated UPR genes compared to all the human promoters using hypergeometric test (equivalent to Fisher's exact test).

\section{Functional enrichment analysis}

To identify enriched biological processes in our gene sets, we used BiNGO ${ }^{51}$ (RRID:nlx_149196) for Cytoscape ${ }^{52}$ (http://apps. cytoscape.org/apps/bingo) (RRID:nif-0000-30404); and GSEA ${ }^{46}$ (RRID:nif-0000-30629) to evaluate if genes from curated Reactome pathways (obtained from the Molecular Signature Database $(\mathrm{MsigDB})^{53}$ ) were statistically over-represented. The significance of each identified biological process or pathway was calculated using the hypergeometric test, adjusted for multiple testing and converted to $f d r$ s using the Benjamini and Hochberg method ${ }^{54}$ implemented in BiNGO (RRID:nlx_149196) or in GSEA (RRID:nif-0000-30629), respectively. We considered only those processes and pathways with an $f d r$ of $\leq 0.05$ to be significantly enriched.

\section{Development of a web-portal for interactive analysis of UPR-associated gene expression}

To enable the visualization and interactive inspection of expression of UPR genes across the integrated experiments, we implemented the UPR-HD tool. It is database with a web-interface based on a modified and enhanced version of the GeneXplorer software ${ }^{55}$. UPR-HD enables the query of individual or multiple UPR genes, the visualization of the expression changes observed in the microarray experiments and their export in table format for further usage. A help page gives an overview of the web-tool's functionalities. UPR-HD can be freely accessed at http://uprhd.sysbiolab.eu.

\section{Results and discussion}

Identification of common UPR genes across HD gene expression studies

To determine possible implications of the UPR in HD, we sought to assess its activation using a computational approach and the evaluation of existing data. First, we catalogued genes that are involved in UPR from several different sources and divided them into three different categories: UPR-KEGG-GO, UPR-Interactions and UPR-Literature as described in Material and Methods section and detailed in Table 1 and Supplementary Figure 1.

Since changes in gene transcription are main effects of UPR activation and published microarray data are available for HD in humans as well as for HD models, we collected 12 different gene expression datasets generated for the study of HD: three datasets included expression from human blood and brain samples as well as human induced pluripotent stem cells (iPSCs); seven datasets were derived from HD mouse models and cell cultures; one from rat cells and one from yeast cells. If the expression dataset constituted timeseries, we split the dataset according to the time points to maintain the temporal aspect of the expression changes.

We reasoned that UPR activity should be reflected in the regulation of UPR genes. By applying GSEA we tested whether UPR genes tend to be differentially expressed in HD samples or models compared to the corresponding controls. GSEA was employed, since it is able to detect modest but consistent tendencies in expression change within a pre-defined set of genes. This can be seen as a crucial advantage, as only small changes in gene expression are frequently observed in the study of neurodegenerative disease due heterogeneity of tissue samples and biological variability of the underlying processes.

Remarkably, we found both indications for significant upregulation as well as repression of UPR genes in the different comparisons. Notably, significant differential expression was generally consistent across the three alternative UPR gene sets (with the exception of 
R6/1 mice at 27 weeks, where UPR-Literature genes tended to be downregulated while UPR-GO-KEGG genes displayed upregulation) (Figure 2). This observation implies that the obtained findings tend to be independent of the particular definition of UPR genes chosen in this study.

For most murine in vivo HD models, a significant upregulation was detected. Interestingly, the activation pattern was dependent on the time point of expression measurement for the two mouse models (R6/1 and YAC128), for which time series data were available. In the case of R6/1 mice, expressing exon 1 of the human HTT gene with a $115 \mathrm{CAG}$ repeat, the most significant activation of UPR genes occurs after 18 and 22 weeks, while genes included in UPR-Literature and UPR-Interactions sets tend to be downregulated after 27 weeks. In contrast, for YAC128 mice containing the full length human HTT gene with 128 CAG repeats, upregulation of UPR genes is only observed at the later time point (24 months), whereas downregulation dominates after 12 months. This divergence may be explained by the rapid development of an aggressive disease phenotype in R6/1 mice compared to YAC128 mice, which show a milder phenotype with slower progression (Figure 2).

Inspecting the three human expression datasets, only the iPSC HD model showed a highly significant activation for all three UPR gene sets, whereas no consistent differential expression of the three UPR gene sets could be detected in blood and brain samples of HD patients. For whole blood samples, this observation might not be surprising, since erythrocytes - constituting the main component of blood - lack of an ER. The absence of a clear pattern in HD brain expression might be due to the fact that expression data were obtained from the post-mortem samples and thus represent typically only the very late stage of the disease. Finally, no significant alterations of expression were found for the rat in vitro and the yeast HD model (Figure 2).

Strikingly, expression of UPR genes also tended to display a strong correlation with the length of the polyglutamine tract in mice. Altogether, the expression of $10.6 \%$ of genes was found to be significantly positively correlated, while $7.8 \%$ were negatively correlated with the number of CAG. More specifically, we obtained p-values of $1.7 \cdot 10^{-5}, 7.7 \cdot 10^{-6}$ and $2.2 \cdot 10^{-16}$ for the overrepresentation of correlated UPR-KEGG-GO, UPR-Interactions and UPRLiterature genes, and p-values of $0.10,3.9 \cdot 10^{-5}$ and $4.6 \cdot 10^{-15}$ for the overrepresentation of anti-correlated genes, respectively.
Next, we sought to identify UPR genes which showed conserved differential regulation in distinct HD models. For this purpose, we collected genes that were assigned to the enrichment core by GSEA in the comparisons that showed significant upregulation of UPR genes. In total we collected the UPR genes contained in the enrichment cores from six murine HD models (including one cell line) and the human HD iPSC model. Intersection of these sets led to the identification of 132 genes that were commonly upregulated, when UPR activation was indicated (Figure 3, Supplementary data file 1). We refer to this set of genes as $U P R-H D^{u p}$.

As the UPR has also been associated with suppression of gene transcription and the enhanced degradation of numerous transcripts ${ }^{56,57}$, we carried out the equivalent procedure to identify UPR genes whose downregulation is conserved in different HD models. Here, we intersected the enrichments core from five comparisons displaying suppression of UPR genes (Supplementary Figure 2, Supplementary data file 2). This resulted in 81 commonly downregulated genes. We refer to the combined set of UPR genes (consisting of 132 upregulated and 81 downregulated genes) that were commonly detected as differentially regulated in HD gene expression data as $U P R-H D^{\text {diff. }}$.

To capture a larger number of dysregulated UPR genes, we generate alternative gene lists with less stringent requirement for inclusion. In particular, we derived 876 upregulated genes by requiring that they needed to be included in the enrichment cores of the human iPSC and only four out of six murine HD models (Supplementary data file 1). Similarly, a less stringent list was generated with 388 genes showing downregulation in at least four comparisons (Supplementary data file 2).

\section{Examining stress response elements in the promoter regions of upregulated UPR genes}

To assess whether the observed upregulation indeed reflects the activation of UPR or if it might be a consequence of other unrelated processes, we carried out an analysis of the promoter regions of genes included in UPR-HD ${ }^{\text {up }}$. We searched for the presence of sequence elements that indicate binding of transcription factors associated with the UPR. In particular, we searched for unfolded protein response elements (UPRE; TGACGTG (G/A)) and the alternative ER stress response elements I (ERSE I; CCAAT(N9)CCACG) and II (ERSE II; ATTGG-N-CCACG) in promoter regions (-1000 bp to $+500 \mathrm{bp})$ regions of UPR-HD ${ }^{\text {up }}$ genes. These characteristic

\begin{tabular}{|c|c|c|c|c|c|c|c|c|c|c|c|c|c|c|c|c|}
\hline Species & Human & Human & Human & Mouse & Mouse & Mouse & Mouse & Mouse & Mouse & Mouse & Mouse & Mouse & Mouse & Mouse & Rat & Yeast \\
\hline Model & HD_CN & HD_blood & HD_iPSC & R6/1_18W & R6/1_22W & R6/1_27W & R6/2_12W & CHL2_22M & Ctip2-/. & YAC128_12M & YAC128_24M & HdhQ111 & CAG150_D4 & CAG150_D6 & $82 Q$ & $4 \mathrm{mut}$ \\
\hline Gene Set & GSE3790 & GSE24250 & GSE37547 & GSE3621 & GSE3621 & GSE3621 & GSE9803 & GSE10202 & GSE9330 & GSE18551 & GSE18551 & GSE3583 & GSE9760 & GSE9760 & GSE12481 & GSE18644 \\
\hline UPR-LIT & -2.61 & -2.03 & 5.06 & 3.05 & 3.12 & -3.09 & 2.77 & 3.33 & 7.23 & -2.17 & 3.58 & 1.98 & -2.5 & -2.95 & -1.06 & -1.35 \\
\hline UPR-GO-KEGG & 1.51 & -0.92 & 3.25 & 2.09 & 2.23 & 1.69 & 2.24 & 2.86 & 3.47 & -1.65 & 2.55 & 1.82 & -2.45 & -2.48 & -1.14 & 0.99 \\
\hline UPR-Interactions & 0.8 & 0.79 & 3.08 & 1.86 & 1.46 & -1.32 & 1.45 & 1.82 & 3.1 & 0.7 & 1.67 & 1.59 & -2.6 & -2.23 & 1.19 & NA \\
\hline
\end{tabular}

Figure 2. Differential regulation of UPR gene sets detected in HD expression data. For each of the compiled UPR genes sets, the normalized enrichment scores (NES) produced by GSEA are shown for different comparisons of HD-associated expression with controls. Positive scores indicate a tendency towards upregulation; negatives scores indicate a tendency towards downregulation of genes in the UPR sets. Comparisons that showed significant upregulation of UPR gene sets ( $f d r \leq 0.05$ and NES $\geq+1.4$ ) are highlighted by red background, while significant downregulation ( $f d r \leq 0.05$ and NES $\leq+1.4$ ) by green background. 

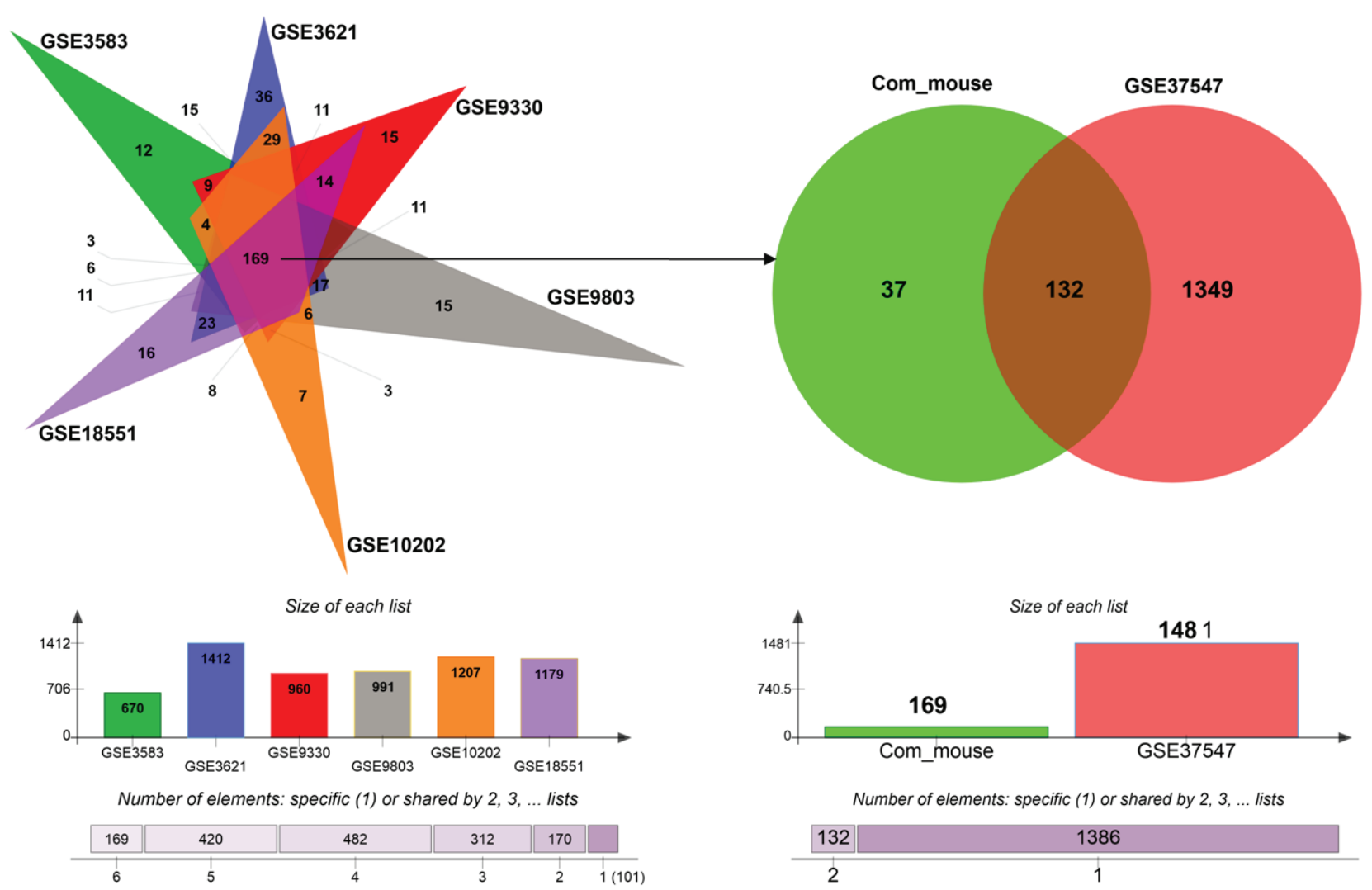

Figure 3. Up regulated UPR genes. Genes included in the core enrichment set for comparisons that indicated UPR activation (highlighted in red in Figure 2) were compared. Common upregulated UPR genes $(n=169)$ in six HD murine models (left side) were intersected with upregulated UPR genes in human HD iPSCs (right side) resulting in a set of 132 UPR genes, whose activation was conserved across the different HD models. The bar plots (bottom) display the number of UPR genes assigned to the core enrichment sets for comparisons that indicated upregulation.

sequence elements are targeted by the bZIP transcription factors ATF6 and XBP1, which are main mediators of the transcriptional adaptation evoked by $\mathrm{UPR}^{58}$.

Strikingly, we found that the vast majority of the UPR-HD ${ }^{\text {up }}$ has such a characteristic binding sequence in their promoter regions (Supplementary Figure 3). Compared to number of sequence elements that we would expect by chance, a highly significant overrepresentation was detected for the UPR-HD ${ }^{\text {up }}$ genes. More specifically, we found the occurrence of UPRE in 104 genes $\left(p=3.0 \cdot 10^{-9}\right)$, ERSE-I in 93 genes $(p=0.0019)$, and ERSE-II in $8(p=0.052)$. Notably, a large number of UPR-HD ${ }^{\text {up }}$ genes had alternative binding motifs included in the promoter region: 70 genes had both ERSE-I and UPRE, 2 genes had both ERSE-I and ERSE-II and six genes had all three elements (for list of genes see Supplementary data file 3) which might suggest that these genes are under particularly tight control of UPR-associated transcription factors ATF6 and XBP1. We also detected a highly significant enrichment for the less stringent list of upregulated UPR genes. Here, we found that 684 genes have UPRE $\left(p=4.4 \cdot 10^{-41}\right), 562$ have ERSE-I $\left(p=4.4 \cdot 10^{-5}\right)$ and 56 have ERSE-II $\left(p=3.8 \cdot 10^{-5}\right)$ in their promoter region (Supplementary data file 3). Altogether, the results of the promoter analysis support the conclusion that the upregulation of UPR genes in HD models faithfully reflects an activated UPR.

\section{Biological processes that are enriched in differentially expressed UPR genes}

Since the UPR comprises a complex series of diverse molecular mechanisms, we examined the functional composition of UPR-HD ${ }^{\text {diff }}$ genes. For this purpose, we performed functional analysis using BiNGO to identify enriched biological processes (as defined in GO) that are overrepresented among UPR-HD ${ }^{\text {diff }}$ genes. All the biological processes that are significantly enriched in our analysis are listed in Supplementary data file 4 as well as those for the less stringent list of differentially regulated UPR genes. Expectedly, we detected that stress-related functional categories such as 'response to stress' (GO ID:6950; $\mathrm{n}=44 ; f d r=2.08 \mathrm{E}-03$ ) and 'response to unfolded protein' (GO ID:6986; $\mathrm{n}=13 ; f d r=4.55 \mathrm{E}-09$ ) were enriched (Figure 4a). A second group of significantly overrepresented GO categories were related to 'protein transport' (GO ID:15031; $\mathrm{n}=34 ; f d r=1.76 \mathrm{E}-07$ ) and 'protein localization' (GO ID:8104; $\mathrm{n}=36 ; f d r=1.19 \mathrm{E}-06)$ including 'vesicle-mediated transport' (GO ID:16192; $\mathrm{n}=24 ; f d r=9.03 \mathrm{E}-05)$ and 'ER to Golgi vesiclemediated transport' (GO ID:6888; $\mathrm{n}=4$; $f d r=4.00 \mathrm{E}-02$ ) (Figure 4b). 


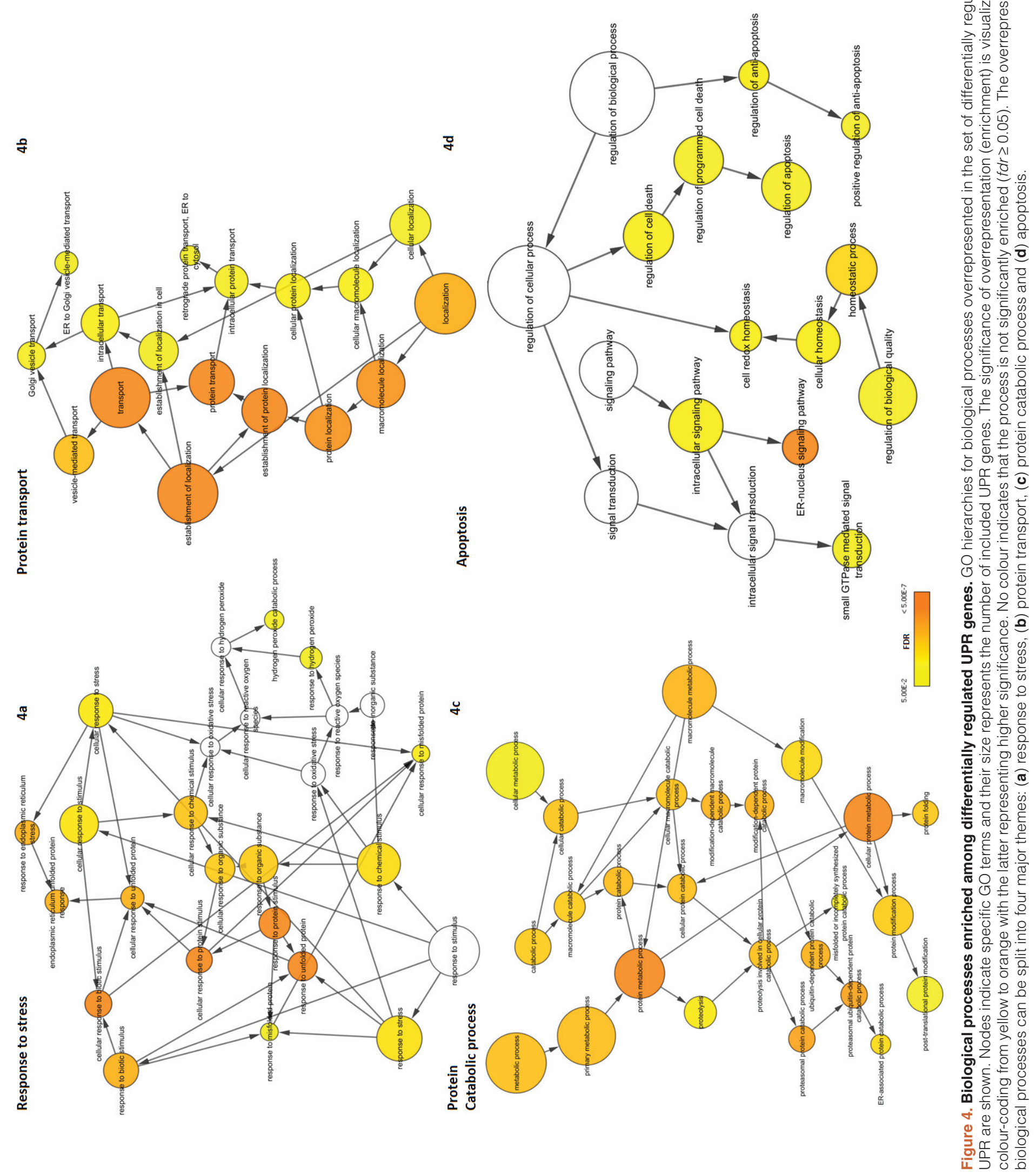


Additionally, we also found 'ER-nucleus signalling pathway' (GO ID:6984; $n=9$; adjp-value $=1.81 \mathrm{E}-07$ ) to be highly enriched. It has been previously reported that ER-nucleus signalling pathway functions via activation of NF- $\kappa \mathrm{B}$ due to ER-overload triggered by protein congestion ${ }^{59}$.

Furthermore, UPR-HD ${ }^{\text {diff }}$ genes tended to be associated with protein catabolism and in particular protein degradation (Figure 4c). Significant processes here were e.g. 'protein catabolic process' (GO ID:30163; n=18; $f d r=6.40 \mathrm{E}-05$ ), 'proteasomal ubiquitindependent protein catabolic process' (GO ID:43161; $n=13$; $f d r=6.69 \mathrm{E}-06$ ) and 'protein ubiquitination' (GO ID:31396; $\mathrm{n}=7$; $f d r=3.12 \mathrm{E}-02$ ). These results coincide well with previous studies establishing the connection of UPR and ERAD and showing, for instance, that the extent of activation of the UPR is concurrent with the severity of ERAD defect ${ }^{60}$.

Finally, genes linked to apoptosis could be found among the UPR-HD ${ }^{\text {diff }}$ genes (Figure 4d). Of particular interest for potential intervention could be genes associated with 'regulation of apoptosis' (GO ID:42981; $\mathrm{n}=24$; $f d r=1.65 \mathrm{E}-02$ ), as their manipulation may prevent the execution of the apoptotic programme under persistent ER stress.

In summary, UPR genes detected as commonly differentially regulated in HD expression data were not restricted to a particular functional category, but can be associated with many processes linked to the UPR.

\section{Pathways enriched in upregulated genes}

Complementary to the functional composition, we evaluated whether specific pathways might be activated based on the observed commonly upregulated UPR genes (UPR-HD ${ }^{\text {up }}$ ). Therefore, we carried out pathway enrichment analysis using a set of pathways curated in the Reactome database. As expected, 'unfolded protein response' ( $\mathrm{n}=6 ; f d r=2.04 \mathrm{E}-05)$, 'activation of genes by ATF4' ( $\mathrm{n}=3 ; f d r=0.00291)$ and 'PERK regulated gene expression' $(\mathrm{n}=3 ; f d r=0.0033)$ were detected as significantly enriched among UPR-HD ${ }^{\text {up }}$ genes (Figure 5). More interestingly, we also found an overrepresentation of components of the 'immune system' $(n=14$; $f d r=6.74 \mathrm{E}-05)$, 'adaptive immune system' ( $\mathrm{n}=6 ; f d r=1.96 \mathrm{E}-03)$, 'NGF signalling' ( $\mathrm{n}=9$; $f d r=2.42 \mathrm{E}-03)$, and 'Diabetes pathways' $(\mathrm{n}=7 ; f d r=2.04 \mathrm{E}-05)$. Complete results from the analysis are included in Supplementary data file 5.

Remarkably, recent studies have also suggested that ER stress and activated UPR are interconnected with inflammatory processes ${ }^{61}$. Inflammation is an immunological process usually carried out by the vascular system to counteract disease, and to fight foreign antigens against invasion. Within the brain, microglia and astrocytes play important immunological functions. Until very recently, little was known about inflammatory molecules in HD. Recent studies, however revealed a distinct profile of inflammatory mediators from post-mortem human HD tissue ${ }^{62,63}$. Inflammatory mediators such as IL-1 $\beta$ and TNF- $\alpha$ were increased only in the striatum, whereas IL-6, IL-8 and MMP-9 were also upregulated in cortex and in the cerebellum $^{63}$. This supports the conjecture that secreted inflammatory

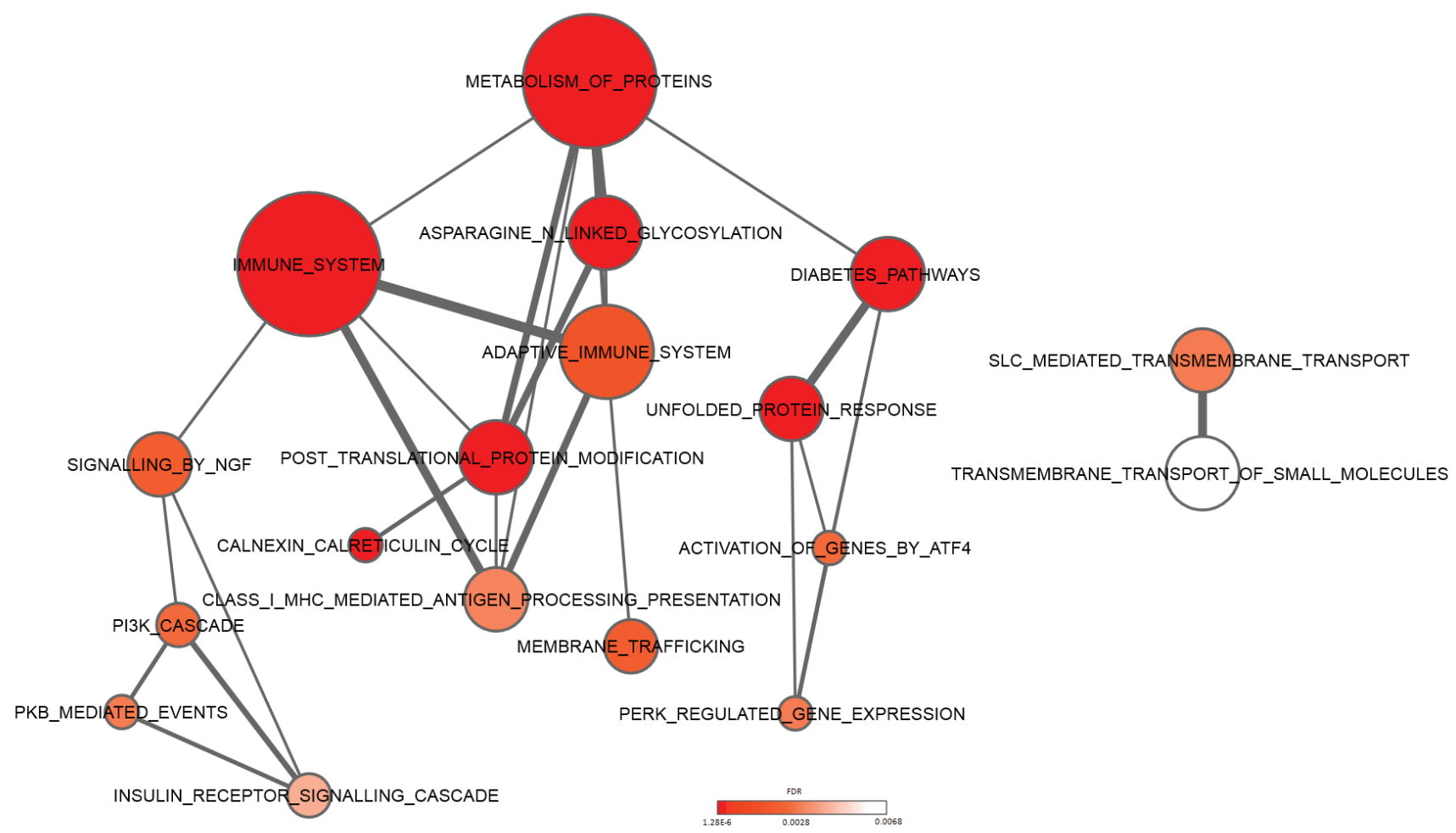

Figure 5. Pathways enriched among upregulated UPR genes. The network of pathways with overrepresentation of upregulated UPR genes are shown. Node size represents number of genes in each pathway and connecting line size represents number of genes shared between two pathways. Colour coding from white to red indicates increasing statistical significance. Pathways were derived from the Reactome database. 
cytokines and activated microglia cells could lead to axonal damage and extensive neuronal cell death in HD pathology ${ }^{62-65}$. In general, activated microglia exert their diverse effects on neurons and macroglia (astrocytes and oligodendrocytes). Inflammation occurs through the release of cytoprotective agents such as growth factors, plasminogen, and neuroprotective cytokine as well as cytotoxic substances such as oxygen radicals, nitricoxide, glutamate, proteases, and neurotoxic cytokines. One of the earliest reports describing microglial abnormalities in HD was provided by Singhrao et al. ${ }^{65}$. Microglial cell counts were considerably increased in the caudate putamen of HD and these microglial cells expressed increased amounts of complement factors. A more detailed investigation of microglial morphological changes associated with HD was performed by Sapp et al. ${ }^{66}$. The authors localized morphologically activated microglial cells in the neostriatum, cortex and globus pallidus as well as in adjoining white matter of HD brains. Additionally, positron emission tomography (PET) studies using the ligand for benzodiazepine receptor (PK-11195), which labels activated microglia have been employed to study of neuroinflammation. Using this technique, Tai et al. ${ }^{67,68}$ demonstrated that microglial activation in HD patients correlates with disease progression as assessed by loss of dopamine D2 receptor binding sites. Interestingly, Tai et al. could also demonstrate that microglial activation and release of cytokine IL- 6 can be observed in presymptomatic HD gene carriers and can be detected up to 15 years before predicted age of onset. These findings indicate the microglial inflammatory activation is an early event associated with subclinical progression of HD and may constitute a target for early therapeutic intervention.

Besides the indication of processes related to the immune response, results of the pathway enrichment analysis also pointed to diabetes. It has been shown that diabetes in Wolcott-Rallison syndrome (a rare autosomal recessive form of juvenile diabetes) is a result of high levels of ER stress caused by mutations in the PERK gene in pancreatic $\beta$-cells. In addition, studies have shown that HD patients show increased incidence of diabetes ${ }^{69,70}$ and HD transgenic mice develop hyperglycemia ${ }^{71,72}$. More recently it has been experimentally validated that HD transgenic mice develop intranuclear inclusions in the pancreatic $\beta$-cells, causing an intrinsic defect in insulin production $^{73}$.

For the enlarged list of upregulated UPR genes, additional pathways were detected to be significantly enriched (Supplementary data file 5). For instance, genes associated with cell cycle and apoptosis were strongly overrepresented among the upregulated UPR genes.

\section{Prioritization of UPR-HD connectors through integrative analysis}

To narrow down the list of UPR-HD ${ }^{\text {diff }}$ genes for further inspection, we utilized additional information, including a reference set of potential molecular targets for HD therapy that were made available through the HD Research Crossroads database initiated by the CHDI Foundation (see Kalathur et al. 2012) ${ }^{41}$. Genes were included by experts in the field based on the evaluation of published literature and in-house screens using a set of defined criteria (see Kalathur et al. 2012) ${ }^{41}$. For instance, a gene was considered as a potential HDTT if genetic or pharmacologic modification of its activity led to a change of a HD-related phenotype in a validated cell culture or organism model of HD. At present, this curated reference set constitutes the most comprehensive collection of HDTTs. In addition, we extracted genes, whose corresponding proteins were reported to be physically associated with HTT, from the HDNetDB database. We recently demonstrated that HTT interactors tend to be enriched in proteins that influence the toxicity of mHTT, and provide favourable candidates for the identification of molecular modifiers of $\mathrm{HD}^{74}$.

We reasoned that differentially regulated UPR genes, which have been shown to influence HD-related phenotypes and to be physically associated with HTT, could constitute molecular links between UPR and HD. Therefore, we integrated the three gene lists and identified 13 genes that were common to all three: RAB5A, $H M G B 1$, CTNNB1, DNM1, TCP1, TUBB, TSG101, DNAJB1, CCT2, EEF2, DYNC1H1, HSPA5 and SLC12A5 (Supplementary Figure 4). Most of the corresponding proteins are indirect interactors of HTT, while two (CTNNB1, DNM1) interact directly (Table 3, Supplementary Figure 4). Notably, the search for stress response elements in the upstream regions of these 13 genes revealed that eight genes (RAB5A, HMGB1, CTNNB1, DNM1, TCP1, TUBB, TSG101 and $D N A J B 1)$ possess either UPRE or ERSE or both elements in their promoters, suggesting that these genes are under direct control of UPR-associated transcription factors (Table 3). Moreover, the expression of the 13 gene tends to be strongly correlated with the length of the polyglutamine tract in HD mice. Indeed, 9 of the 13 genes were found to be significantly correlated, whereas we would expect only 1.4 by chance.

Inspection of the genes possessing UPRE or ERSE elements in their promoter regions revealed that four of them (TCP1, CCT2, $D N A J B 1$ and $H M G B 1$ ) have been reported to act as chaperones. Besides being essential components of the UPR, molecular chaperones can modulate the aggregation and toxicity of proteins, including mHTT. TCP1 (CCT1) and CCT2 are components of the TCP1 ring complex (TRiC) that uses cycles of ATP-binding and hydrolysis to bind unfolded polypeptides and facilitate their folding. Notably, TRiC has been identified as a potent suppressor of mHTT mediated toxicity and inhibitor of the $\mathrm{mHTT}$ protein aggregation in vitro and in vivo ${ }^{75}$. DNAJB1 belongs to the group of DnaJ/Hsp40 (Heat shock protein 40) proteins that are involved in protein translation, folding and translocation through regulating ATPase activity of the Hsp70s chaperones. In a PC12 cell model, experiments indicated that DNAJB1 attaches to soluble mHTT oligomers and recruits Hsp70 suppressing mHTT mediated toxicity ${ }^{76}$. Finally, HMGB1 encodes for the High-mobility group box 1 protein (HMGB1), which has recently been demonstrated to have chaperone-like activity, inhibiting aggregation of various proteins. Overexpression of HMGB1 can also decrease the aggregation induced by extended polyQ stretches ${ }^{77}$.

Intersecting the less stringent list of differentially regulated UPR genes with HTT interactors and HDTT led to the identification of additional 40 genes that might link UPR and HD (Supplementary dataset 9). Of particular interest might be 15 genes, whose corresponding proteins are direct interactors of HTT. They include ubiquilin 1 (UBQLN1), the ubiquitin ligase synoviolin (SYVN1) involved in ERAD and the ubiquitin ligase $A T G 5$, which is 
Table 3. Differentially regulated UPR genes that interact with HTT and were classified as potential HD therapeutic targets (HDTT). + indicates the presence of ER stress-associated sequence motifs (UPRE, ERSE-I, ERSE-II) in the promoter regions (+1000 to $-500 \mathrm{bp})$. Interaction type indicates whether the protein was shown to have a direct or indirect physical interaction. The Spearman correlation coefficient and the corresponding estimated fdr describe the correlation of gene expression with the length of polyglutamine tract in $\mathrm{HD}$ mice.

\begin{tabular}{|c|c|c|c|c|c|c|}
\hline Gene & UPRE & ERSE-I & ERSE-II & $\begin{array}{l}\text { Interaction } \\
\text { type }\end{array}$ & $\begin{array}{l}\text { CAG } \\
\text { correlation } \\
\text { coefficient }\end{array}$ & fdr cor. \\
\hline RAB5A & + & + & & Indirect & 0.48 & 0.0038 \\
\hline HMGB1 & + & + & & Indirect & 0.39 & 0.026 \\
\hline CTNNB1 & & + & & Direct & 0.82 & 0 \\
\hline DNM1 & + & + & & Direct & 0.55 & 0.00050 \\
\hline TCP1 & + & + & & Indirect & 0.62 & 0.00014 \\
\hline TUBB & + & + & & Indirect & 0.60 & 0.00025 \\
\hline TSG101 & + & + & & Indirect & 0.73 & 0 \\
\hline DNAJB1 & + & & + & Indirect & -0.22 & 1 \\
\hline ССТ2 & & & & Indirect & 0.79 & 0 \\
\hline EEF2 & & & & Indirect & 0.81 & 0 \\
\hline DYNC1H1 & & & & Indirect & 0.57 & 0.00038 \\
\hline HSPA5 & & & & Indirect & 0.07 & 0.81 \\
\hline SLC12A5 & & & & Indirect & -0.06 & 1 \\
\hline
\end{tabular}

necessary for autophagy, as well as the initator (CASP2) and effector $(C A S P 7)$ caspases. Moreover, the major molecular regulators such as TP53, AKT1 and SPI are members of this candidate set.

\section{Linking the UPR network to apoptosis and HTT}

A crucial aspect of the UPR in the context of HD is the possibility that it can trigger apoptosis upon persistent ER stress. To obtain a comprehensive view of the connections between UPR and apoptosis, we applied a network approach. First, we generated the UPR interactome from known protein interactions of UPR core components, which we extracted from the UniHI and HDNetDB databases (Supplementary data file 6). Second, we compiled a list of genes $(n=594)$ associated with apoptosis from several different sources (as described in the materials and methods). We then used this list to identify 40 proteins associated with apoptosis within the UPR interactome (Supplementary data file 7). These genes included, among others, Apoptosis Signal Regulating Kinase 1 (ASK1, also known as MAP3K5), whose knock-out in primary neuron provided protection from ER stress-induced JNK activation and cell death triggered by polyQ fragments ${ }^{78}$.

As the mutation in HTT can perturb the function of interacting proteins by aberrant binding, we checked for each of the 40 proteins whether they have been reported to physically associate with HTT. Using molecular interaction data collected in HDNetDB, we detected that six of the 40 proteins interact with HTT i.e. ADD1,
HSP90B1, IKBKB, RPS3A, IKBKG and LMNB1 (Supplementary data file 7). A visualisation of the UPR interactome with apoptosisrelated proteins and HTT interactors highlighted can be found in Figure 6.

Literature review showed that the two proteins kinases IKBKB and IKBKG, the laminin LMNB1 and the ribosomal protein RPS3A have been previously linked to neurodegenerative diseases. IKBKB and IKBKG are subunits of IkB kinase (IKK). They activate members of the NF- $\kappa B$ transcription factor family by phosphorylation of their inhibitor $(\mathrm{IkB})^{79}$ leading to ubiquitination and destruction of IkB, thereby allowing activation of the NF- $\kappa \mathrm{B}$ complex. NF- $\kappa \mathrm{B}$ maintains the balance between cell survival and apoptosis ${ }^{80}$. Although unrelated to ER stress, it has been shown that inhibition of IKBKB decreases HTT proteolysis in a cell model, and thus might lower the load of toxic HTT fragments in HD ${ }^{81}$. Recently, it has been reported that ubiquitination of IKBKG by Parkin, an ubiquitin ligase associated with Parkinson's disease regulates the anti-apoptotic pathway that is key to maintaining mitochondrial integrity $^{82}$.

Lamin B1 protein, LMNB1 is thought to be involved in nuclear stability and chromatin structure. Experiments in Caenorhabditis elegans overexpressing aggregation-prone peptides identified laminins as modulators of protein toxicity at neuromuscular junctions ${ }^{83}$. Further, in leukodystrophy mouse models, lamin B1 acts as an 


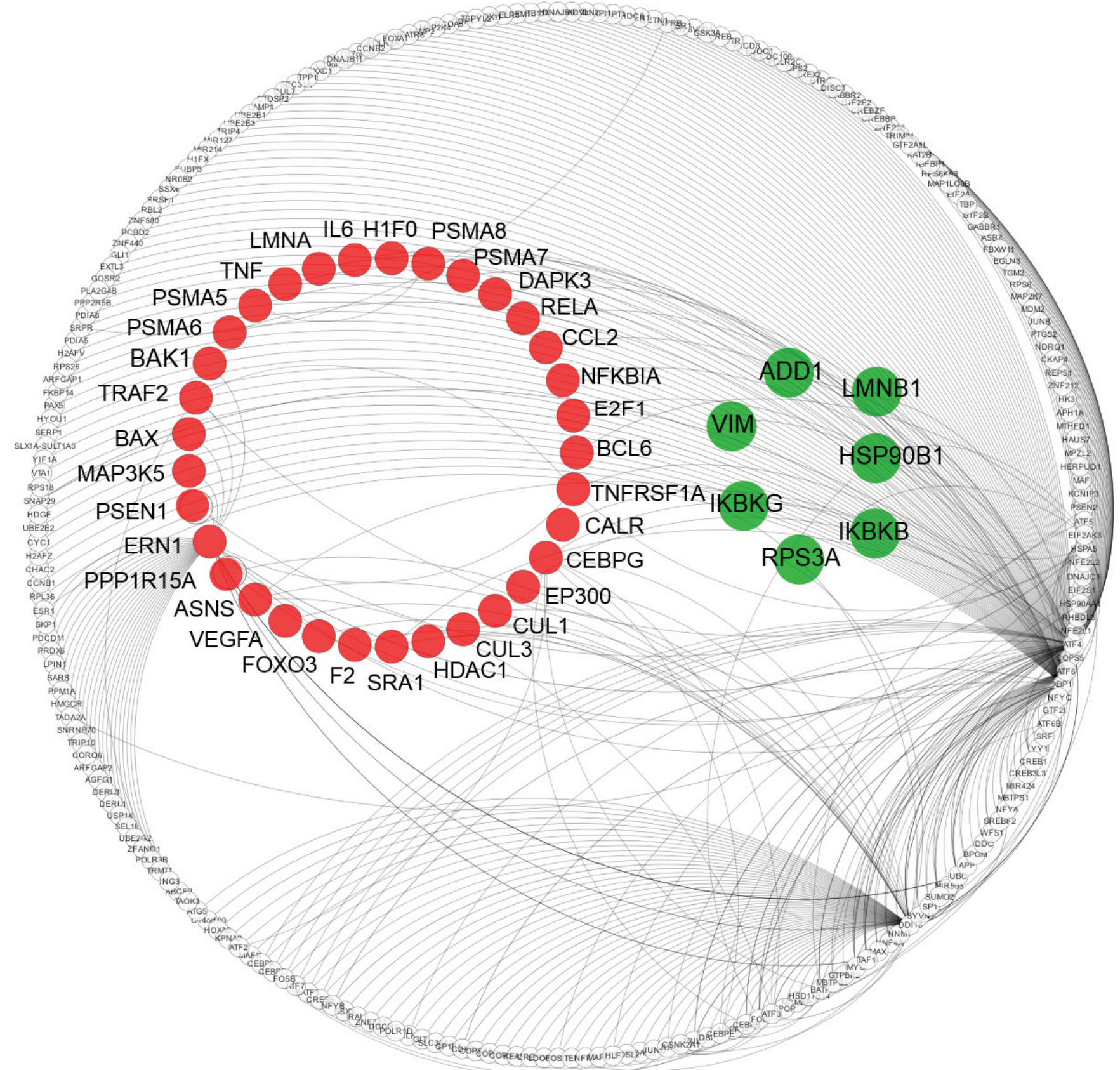

Figure 6. Network representation of UPR-apoptosis connection. The network displays UPR proteins and their interactions. Nodes indicate proteins and lines represent molecular interactions between them as derived from UniHI and HDNetDB. UPR proteins which are also associated with apoptosis are highlighted in red, while UPR proteins that are both associated with apoptosis and identified as HTT interactors are in green. 
important regulator of myelin formation and maintenance ${ }^{84}$, while in humans lamin B1 gene duplications ${ }^{85}$ and large deletions upstream of promoter regions can cause autosomal-dominant leukodystrophy ${ }^{86}$. More importantly, a recent study reports increased levels of lamin B1 in both human HD patients and the R6/1 mouse model of $\mathrm{HD}^{87}$. Due to the involvement of lamin B1 in several cellular alterations such as chromatin organisation, gene transcription and proteotoxicity, alterations in lamin B1 expression might have important implications in HD pathophysiology.

Finally, it has been demonstrated that apoptosis is induced by inhibiting the expression of ribosomal protein S3A (RPS3A) ${ }^{88}$. It also has been observed that SNP variants in RPS3A homologues are associated with pathogenesis of Alzheimer's disease ${ }^{89}$. Apart from its function as a ribosomal protein, RPS3A might also act as a chaperone. Co-expression of mouse RPS3A suppressed the toxicity induced by $\alpha$-synuclein (which is a major components of Lewy bodies observed in Parkinson's disease) in a yeast model system ${ }^{90}$.

As the literature review indicated, the intersection of the UPR interactome with apoptosis-related genes and HTT interactors can point out proteins with potential relevance for neurodegeneration. Thus, the generated gene lists provided in the Supplementary data file 6 and Supplementary data file 7 might give interested researchers a valuable basis for more detailed inspections.

Raw data for Kalathur et al., 2015 'The unfolded protein response and its potential role in Huntington's disease elucidated by a systems biology approach'

9 Data Files

http://dx.doi.org/10.6084/m9.figshare.3080608

\section{Conclusions}

Various studies have indicated a role of the UPR in HD. However, its relevance for therapeutic interventions remains to be established. With the presented work, we aimed to delineate the connection between UPR and HD by examining available HD-relevant gene expression and molecular interaction data. We found indications for differential regulation of UPR genes in a number of expression studies. Notably, the observed differential regulation is not conserved across all evaluated studies reflecting the well-known heterogeneity of current HD models. This needs to be taken into account for future studies of the UPR in the context of HD. The results of our analysis (displayed in Figure 2) may therefore serve as guidance for the choice of model systems. Despite the observed heterogeneity, the comparison nevertheless indicated a number of genes that tend to be commonly regulated in different expression studies. This finding enabled us to define core sets of UPR genes that were commonly up- or downregulated in different studies. This derivation was supported by the detection of a significant overrepresentation of UPR-associated stress response elements (UPRE and ERSE) in the promoter regions of the upregulated genes. Moreover, we observed that expression of UPR genes in the striatum tend to correlate with the length of the HTT polyglutamine tract in mice. This is a remarkable observation, since human patients with longer polyglutamine tracts frequently display earlier age of disease onset and death. The observed strong correlation suggests that the UPR might contribute to dynamics of $\mathrm{HD}$, and thus might present a prime target for inventions aiming to delay the appearance of symptoms and to decelerate disease progression.

Functional enrichment analysis on differentially expressed UPR genes pointed to a broad range of mechanisms involved. Additional pathway analyses indicated the activation of inflammatory processes and a potential connection to diabetes. Including complementary data sets, we identified UPR genes that have been indicated to influence HD pathogenesis. Finally, we derived sets of genes that connect UPR with apoptosis and might be directly influenced by mHTT.

In summary, through our work we present the first comprehensive analysis of UPR activation in HD and elucidate potential links to pathogenetic mechanisms within a systems biology framework. While our work cannot provide definite proofs for the identified relations due to its purely computational nature, it can nevertheless constitute a broad basis for experimental follow-up investigations. To assist such endeavours, extensive Supplementary material has been provided together with this article with the aim of helping independent researchers to select genes of interest. We have developed also a publicly accessible web-portal (http://uprhd.sysbiolab.eu) for the retrieval and visualisation of changes in UPR-associated gene expression across the evaluated transcriptomics studies. In conclusion, we hope that our work can contribute to a better understanding of the UPR in HD and eventually to the identification of novel therapeutic targets to cure HD.

\section{Data availability}

Figshare: Raw data for Kalathur et al., 2015 'The unfolded protein response and its potential role in Huntington's disease elucidated by a systems biology approach' doi: 10.6084/m9.figshare.308060891

\section{Author contributions}

RK collected the data, performed the analysis and prepared manuscript. JGL, SM, TB and KA collected data and wrote parts of manuscript. MF and TB developed the complementary web-tool. MF conceived the study, contributed to interpretation of the results and wrote the final version of the manuscript. All authors agreed to the final content of the manuscript.

\section{Competing interests}

No competing interests were disclosed.

\section{Grant information}

The work presented was supported by CHDI Foundation (A-2666) and by the Portuguese Fundação para a Ciência e a Tecnologia (SFRH/BPD/70718/2010 to RKK and IF/00881/2013 to MEF).

\section{Acknowledgements}

We would like to thank Isabel Duarte for critical reading of the manuscript. 


\section{Supplementary information}
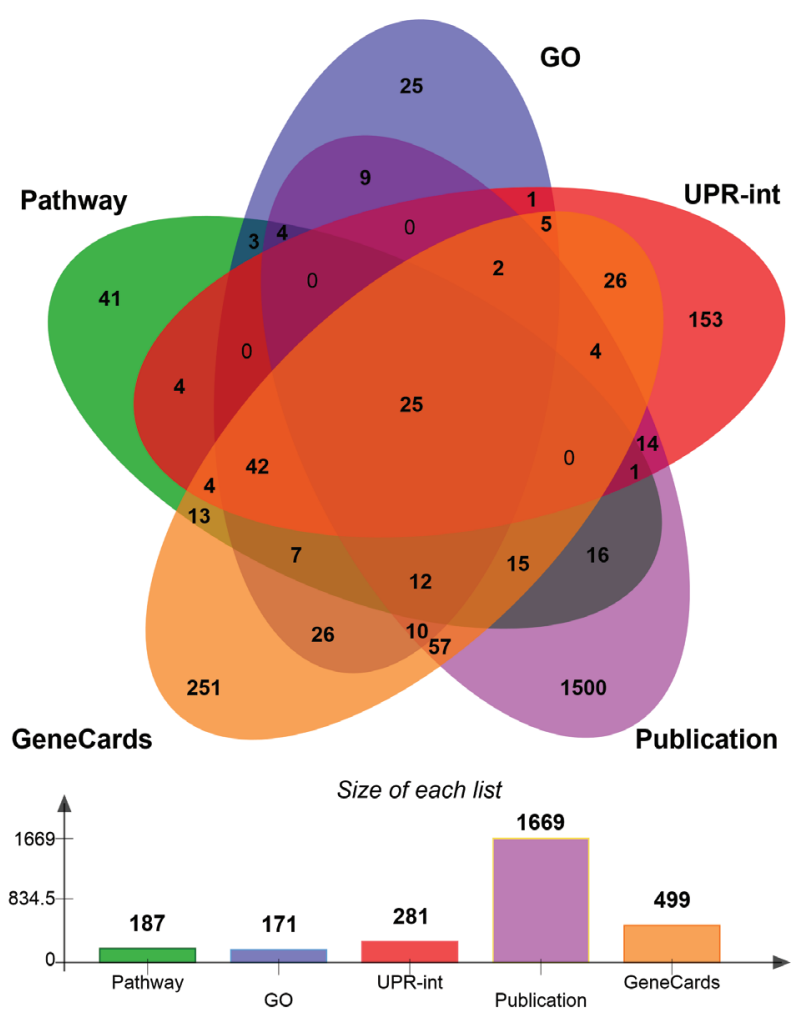

Number of elements: specific (1) or shared by 2, 3, ... lists

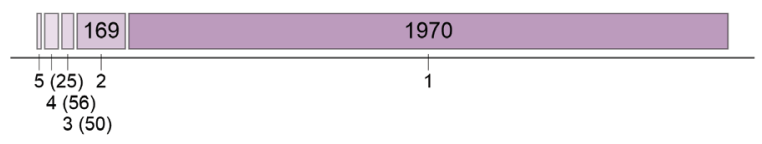

Supplementary Figure 1. Comparison of UPR gene lists. Venn diagram comparing the three different UPR genes lists generated.
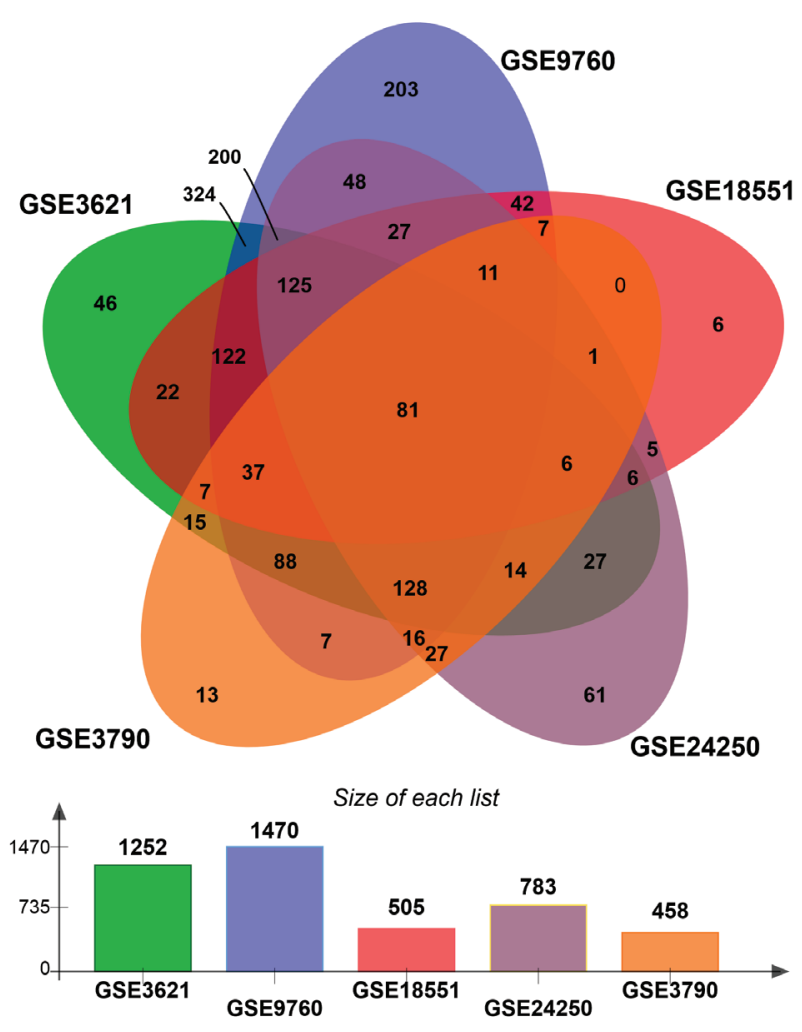

Number of elements: specific (1) or shared by 2, 3, ... lists

\begin{tabular}{|c|c|c|c|c|}
\hline & 307 & 488 & 521 & 329 \\
\hline $5(81)$ & & 3 & 2 & 1
\end{tabular}

Supplementary Figure 2. Common downregulated UPR genes. Comparison of several HD expression data sets to identify UPR genes that are downregulated in different HD models. 


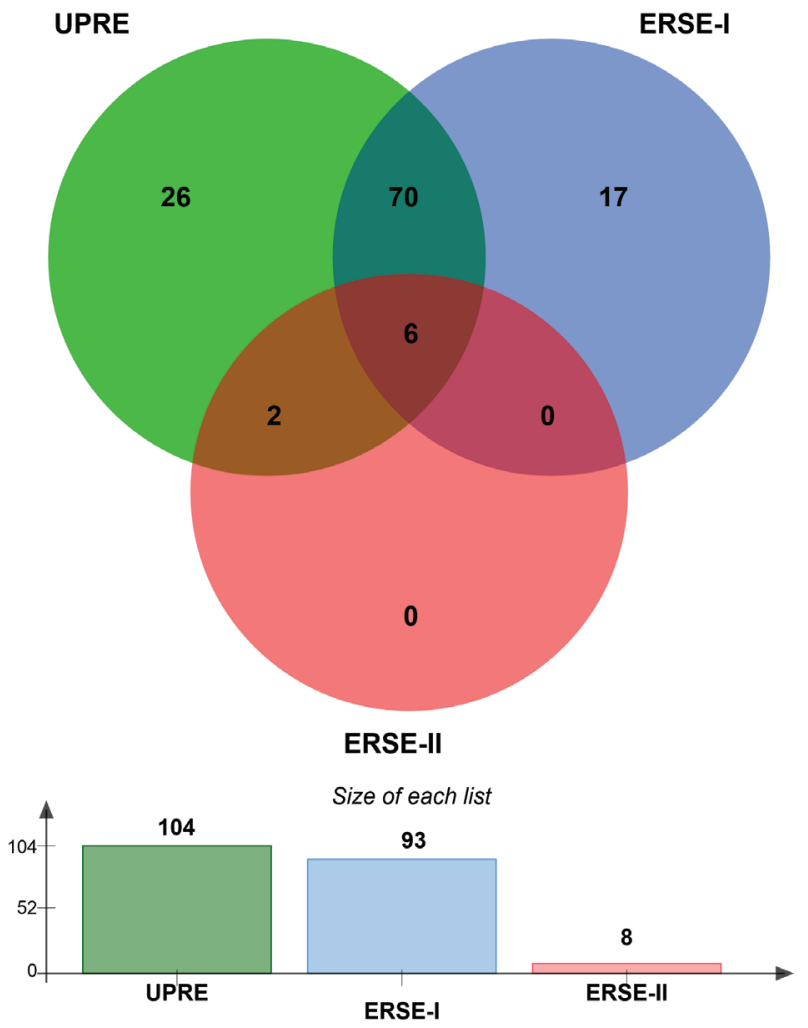

Number of elements: specific (1) or shared by $2,3, \ldots$ lists

\begin{tabular}{c|c|c|}
\hline & 72 & 43 \\
\hline $3(6)$ & 2 & 1
\end{tabular}

Supplementary Figure 3. Comparison of UPRE and ERSE elements in the promoter region of UPR genes that are upregulated in HD.

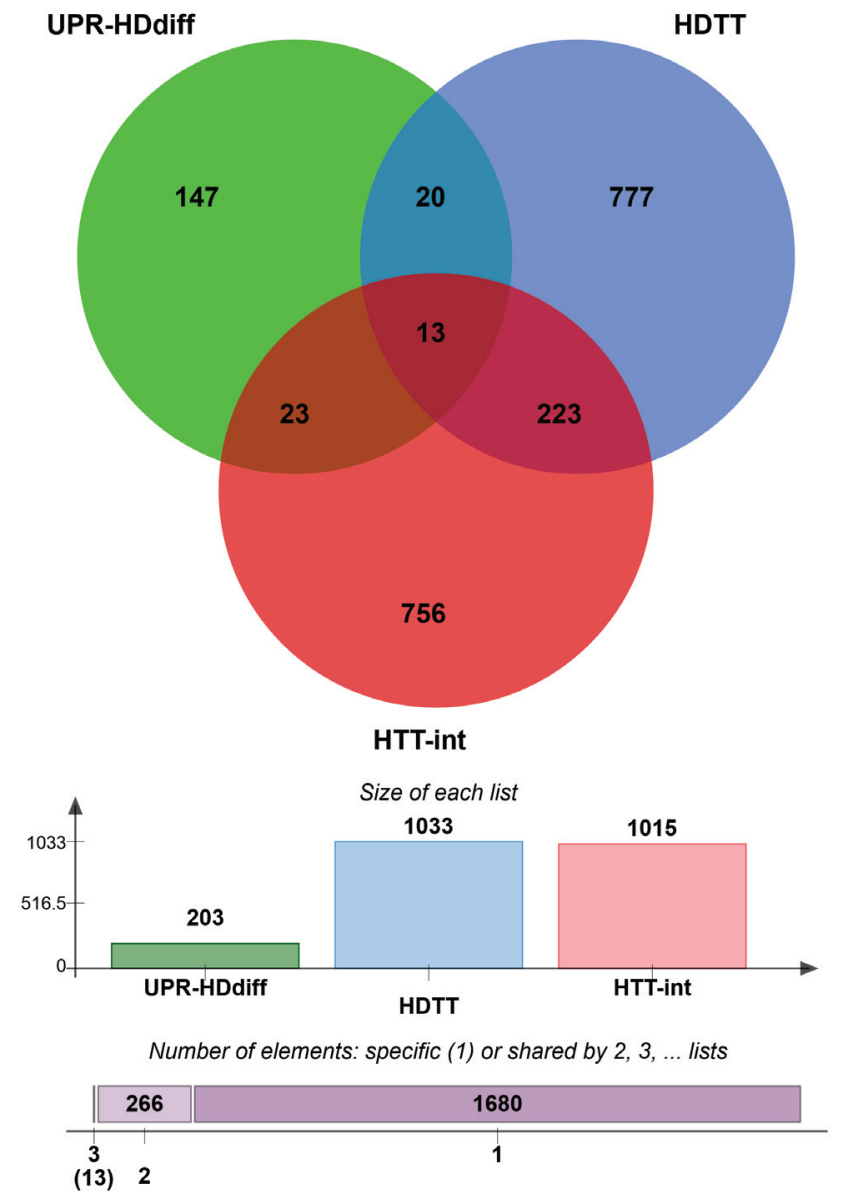

Supplementary Figure 4. UPR-HD connectors. Venn diagram showing common genes between 3 data sets, high stringency UPR-HD diff: UPR genes that are differentially regulated in HD i.e. either upregulated in human HD iPSC and 6 murine HD models or downregulated in 5 murine HD models; HDTT: HD therapeutic targets as described by Kalathur RK et al. ${ }^{41}$ and originated by the HDCrossRoads database; and HTT-int: HTT interactors derived from the HDNetDB. 


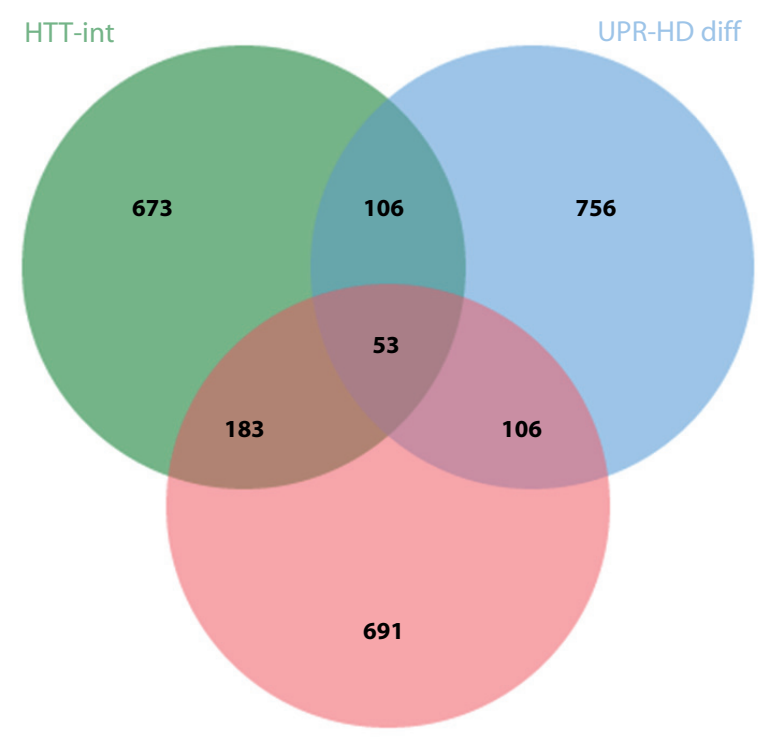

HDTT

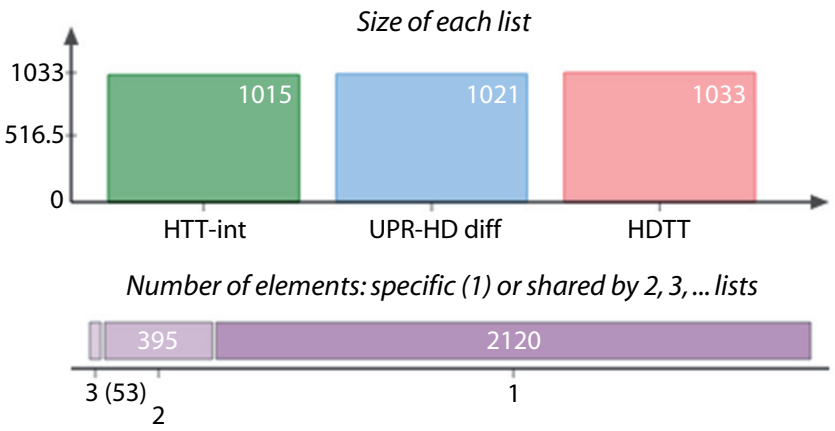

Supplementary Figure 5. UPR-HD connectors for low stringency UPR-HD diff. Venn diagram showing common genes between 3 data sets, low stringency UPR-HDdiff: UPR genes that are differentially regulated in HD i.e. either upregulated in human HD iPSC and at least 4 of 6 murine HD models or downregulated in 4 murine HD models; HDTT: HD therapeutic targets as described by Kalathur RK et al. ${ }^{41}$ and originated by the HDCrossRoads database; and HTT-D-int: direct HTT interactors derived from the HDNetDB.

1. A novel gene containing a trinucleotide repeat that is expanded and unstable on Huntington's disease chromosomes. The Huntington's Disease Collaborative Research Group. Cell. 1993; 72(6): 971-83.

PubMed Abstract | Publisher Full Text

2. Cattaneo $E$, Zuccato $C$, Tartari $M$ : Normal huntingtin function: an alternative approach to Huntington's disease. Nat Rev Neurosci. 2005; 6(12): 919-30. PubMed Abstract | Publisher Full Text

3. $\mathrm{Li} \mathrm{SH}, \mathrm{Li} \mathrm{XJ}$ : Huntingtin-protein interactions and the pathogenesis of Huntington's disease. Trends Genet. 2004; 20(3): 146-54. PubMed Abstract | Publisher Full Text

4. Raymond LA, André VM, Cepeda C, et al: Pathophysiology of Huntington's disease: time-dependent alterations in synaptic and receptor function. Neuroscience. 2011; 198: 252-73.

PubMed Abstract | Publisher Full Text | Free Full Text

5. Beal MF, Kowall NW, Ellison DW, et al.: Replication of the neurochemical characteristics of Huntington's disease by quinolinic acid. Nature. 1986; 321(6066): 168-71.

PubMed Abstract | Publisher Full Text
6. Arrasate M, Finkbeiner S: Protein aggregates in Huntington's disease. Exp Neurol. 2012; 238(1): 1-11.

PubMled Abstract | Publisher Full Text | Free Full Text

7. Becher MW, Kotzuk JA, Sharp AH, et al.: Intranuclear neuronal inclusions in Huntington's disease and dentatorubral and pallidoluysian atrophy: correlation between the density of inclusions and IT15 CAG triplet repea length. Neurobiol Dis. 1998; 4(6): 387-97.

PubMed Abstract | Publisher Full Text

8. DiFiglia M, Sapp E, Chase KO, et al.: Aggregation of huntingtin in neuronal intranuclear inclusions and dystrophic neurites in brain. Science. 1997; 277(5334): 1990-3.

PubMed Abstract | Publisher Full Text

9. Gutekunst $\mathrm{CA}, \mathrm{Li} \mathrm{SH}, \mathrm{Yi} \mathrm{H}$, et al:: Nuclear and neuropil aggregates in Huntington's disease: relationship to neuropathology. J Neurosci. 1999; 19(7): 2522-34. PubMed Abstract

10. Sugars KL, Rubinsztein DC: Transcriptional abnormalities in Huntington disease. Trends Genet. 2003; 19(5): 233-8. PubMed Abstract | Publisher Full Text 
11. Forman MS, Lee VM, Trojanowski JQ: 'Unfolding' pathways in neurodegenerative disease. Trends Neurosci. 2003; 26(8): 407-10. PubMed Abstract | Publisher Full Text

12. Vidal R, Caballero B, Couve A, et al.: Converging pathways in the occurrence of endoplasmic reticulum (ER) stress in Huntington's disease. Curr Mol Med. 2011; 11(1): 1-12.

PubMed Abstract | Publisher Full Text

13. Matus S, Glimcher LH, Hetz C: Protein folding stress in neurodegenerative diseases: a glimpse into the ER. Curr Opin Cell Biol. 2011; 23(2): 239-52. PubMed Abstract | Publisher Full Text

14. Rutkowski DT, Kaufman RJ: That which does not kill me makes me stronger: adapting to chronic ER stress. Trends Biochem Sci. 2007; 32(10): 469-76. PubMed Abstract | Publisher Full Text

15. Bernales S, McDonald KL, Walter P: Autophagy counterbalances endoplasmic reticulum expansion during the unfolded protein response. PLOS Biol. 2006; 4(12): e423.

PubMed Abstract | Publisher Full Text | Free Full Text

16. Matus S, Lisbona F, Torres M, et al:: The stress rheostat: an interplay between the unfolded protein response (UPR) and autophagy in neurodegeneration. Curr Mol Med. 2008; 8(3): 157-72.

PubMed Abstract | Publisher Full Tex

17. Kim I, Xu W, Reed JC: Cell death and endoplasmic reticulum stress: disease relevance and therapeutic opportunities. Nat Rev Drug Discov. 2008; 7(12): 1013-30.

PubMed Abstract | Publisher Full Text

18. Sherman MY, Goldberg AL: Cellular defenses against unfolded proteins: a cell biologist thinks about neurodegenerative diseases. Neuron. 2001; 29(1): 15-32. PubMed Abstract | Publisher Full Text

19. Alves-Rodrigues A, Gregori L, Figueiredo-Pereira ME: Ubiquitin, cellular inclusions and their role in neurodegeneration. Trends Neurosci. 1998; 21(12): 516-20. PubMed Abstract | Publisher Full Text

20. Soto $\mathrm{C}$ : Unfolding the role of protein misfolding in neurodegenerative diseases. Nat Rev Neurosci. 2003; 4(1): 49-60. PubMed Abstract | Publisher Full Text

21. Hughes A, Jones L: Huntingtin localisation studies - a technical review. PLoS Curr. 2011; 3: RRN1211.

PubMled Abstract | Publisher Full Text | Free Full Text

22. Duennwald ML, Lindquist S: Impaired ERAD and ER stress are early and specific events in polyglutamine toxicity. Genes Dev. 2008; 22(23): 3308-19. PubMed Abstract | Publisher Full Text | Free Full Text

23. Atwal RS, Xia J, Pinchev D, et al.: Huntingtin has a membrane association signal that can modulate huntingtin aggregation, nuclear entry and toxicity. Hum Mol Genet. 2007; 16(21): 2600-2615. PubMed Abstract | Publisher Full Text

24. Atwal RS, Truant R: A stress sensitive ER membrane-association domain in Huntingtin protein defines a potential role for Huntingtin in the regulation of autophagy. Autophagy. 2008; 4(1): 91-93.

PubMled Abstract | Publisher Full Text

25. Vidal RL, Figueroa A, Court FA, et al.: Targeting the UPR transcription factor XBP1 protects against Huntington's disease through the regulation of FoxO1 and autophagy. Hum Mol Genet. 2012; 21(10): 2245-62. PubMed Abstract | Publisher Full Text | Free Full Text

26. Lajoie $\mathrm{P}$, Snapp EL: Changes in BiP availability reveal hypersensitivity to acute endoplasmic reticulum stress in cells expressing mutant huntingtin. $J$ Cell Sci. 2011; 124(Pt 19): 3332-43.

PubMled Abstract | Publisher Full Text | Free Full Text

27. Ashburner M, Ball CA, Blake JA, et al:: Gene ontology: tool for the unification of biology. The Gene Ontology Consortium. Nat Genet. 2000; 25(1): 25-9. PubMled Abstract | Publisher Full Text | Free Full Text

28. Croft D, Mundo AF, Haw R, et al:: The Reactome pathway knowledgebase. Nucleic Acids Res. 2014; 42(Database issue): D472-7. PubMed Abstract | Publisher Full Text | Free Full Text

29. Kanehisa M, Goto S, Sato $Y$, et al:: Data, information, knowledge and principle: back to metabolism in KEGG. Nucleic Acids Res. 2014; 42(Database issue): D199-205.

PubMed Abstract | Publisher Full Text | Free Full Text

30. Kalathur RK, Pinto JP, Hernandez-Prieto MA, et al.: UniHI 7: an enhanced database for retrieval and interactive analysis of human molecular interaction networks. Nucleic Acids Res. 2014; 42(Database issue): D408-14. PubMled Abstract | Publisher Full Text | Free Full Text

31. Labunskyy VM, Gerashchenko MV, Delaney JR, et al.: Lifespan extension conferred by endoplasmic reticulum secretory pathway deficiency requires induction of the unfolded protein response. PLoS Genet. 2014; 10(1): e1004019. PubMed Abstract | Publisher Full Text | Free Full Text

32. Travers KJ, Patil CK, Wodicka L, et al.: Functional and genomic analyses reveal an essential coordination between the unfolded protein response and ER-associated degradation. Cell. 2000; 101(3): 249-58. PubMed Abstract | Publisher Full Text

33. Jonikas MC, Collins SR, Denic V, et al:: Comprehensive characterization of genes required for protein folding in the endoplasmic reticulum. Science. 2009; 323(5922): 1693-7.

PubMed Abstract | Publisher Full Text | Free Full Text

34. Christianson JC, Olzmann JA, Shaler TA, et al:: Defining human ERAD networks through an integrative mapping strategy. Nat Cell Biol. 2011; 14(1): 93-105. PubMed Abstract | Publisher Full Text | Free Full Text

35. Safran M, Dalah I, Alexander J, et al.: GeneCards Version 3: the human gene integrator. Database (Oxford). 2010; 2010: baq020.

PubMed Abstract | Publisher Full Text | Free Full Text

36. Portt L, Norman G, Clapp C, et al.: Anti-apoptosis and cell survival: a review. Biochim Biophys Acta. 2011; 1813(1): 238-59.

PubMed Abstract | Publisher Full Text

37. Bursch W, Ellinger A, Gerner C, et al.: Programmed cell death (PCD). Apoptosis, autophagic PCD, or others? Ann N Y Acad Sci. 2000; 926: 1-12. PubMed Abstract | Publisher Full Text

38. Blomgren K, Leist M, Groc L: Pathological apoptosis in the developing brain. Apoptosis. 2007; 12(5): 993-1010.

PubMed Abstract | Publisher Full Text

39. Ouyang L, Shi Z, Zhao S, et al:: Programmed cell death pathways in cancer: a review of apoptosis, autophagy and programmed necrosis. Cell Prolif. 2012; 45(6): 487-98.

PubMed Abstract | Publisher Full Text

40. Bredesen DE: Programmed cell death mechanisms in neurological disease. Curr Mol Med. 2008; 8(3): 173-86. PubMed Abstract | Publisher Full Text

41. Kalathur RK, Hernández-Prieto MA, Futschik ME: Huntington's disease and its therapeutic target genes: a global functional profile based on the HD Research Crossroads database. BMC Neurol. 2012; 12: 47. PubMed Abstract | Publisher Full Text | Free Full Text

42. Barrett T, Wilhite SE, Ledoux P, et al.: NCBI GEO: archive for functional genomics data sets--update. Nucleic Acids Res. 2013; 41(Database issue) D991-5.

PubMed Abstract | Publisher Full Text | Free Full Text

43. Gentleman RC, Carey VJ, Bates DM, et al.: Bioconductor: open software development for computational biology and bioinformatics. Genome Biol. 2004; 5(10): R80.

PubMed Abstract | Publisher Full Text | Free Full Text

44. Ritchie ME, Phipson B, Wu D, et al.: limma powers differential expression analyses for RNA-sequencing and microarray studies. Nucleic Acids Res. 2015; 43(7): e47.

PubMed Abstract | Publisher Full Text

45. Gray KA, Yates B, Seal RL, et al:: Genenames.org: the HGNC resources in 2015. Nucleic Acids Res. 2015; 43(Database issue): D1079-85. PubMed Abstract | Publisher Full Text | Free Full Text

46. Subramanian A, Tamayo P, Mootha VK, et al.: Gene set enrichment analysis: a knowledge-based approach for interpreting genome-wide expression profiles. Proc Natl Acad Sci U S A. 2005; 102(43): 15545-50.

PubMed Abstract | Publisher Full Text | Free Full Text

47. Bardou $P$, Mariette $J$, Escudié $F$, et al:: jvenn: an interactive Venn diagram viewer. BMC Bioinformatics. 2014; 15: 293. PubMed Abstract | Publisher Full Text | Free Full Text

48. Yamamoto $\mathrm{K}$, Yoshida $\mathrm{H}$, Kokame $\mathrm{K}$, et al: Differential contributions of ATF6 and $\mathrm{XBP} 1$ to the activation of endoplasmic reticulum stress-responsive cis-acting elements ERSE, UPRE and ERSE-II. J Biochem. 2004; 136(3): 343-50. PubMed Abstract | Publisher Full Text

49. Dreos R, Ambrosini G, Périer RC, et al: The Eukaryotic Promoter Database: expansion of EPDnew and new promoter analysis tools. Nucleic Acids Res. 2015; 43(Database issue): D92-6.

PubMed Abstract | Publisher Full Text | Free Full Text

50. Thomas-Chollier M, Defrance M, Medina-Rivera A, et al:: RSAT 2011: regulatory sequence analysis tools. Nucleic Acids Res. 2011; 39(Web Server issue): W86-91. PubMed Abstract | Publisher Full Text | Free Full Text

51. Maere S, Heymans K, Kuiper M: BiNGO: a Cytoscape plugin to assess overrepresentation of gene ontology categories in biological networks. Bioinformatics. 2005; 21(16): 3448-9. PubMed Abstract | Publisher Full Text

52. Shannon $\mathrm{P}$, Markiel A, Ozier O, et al:: Cytoscape: a software environment for integrated models of biomolecular interaction networks. Genome Res. 2003; 13(11): 2498-504.

PubMed Abstract | Publisher Full Text | Free Full Text

53. Liberzon A: A description of the Molecular Signatures Database (MSigDB) Web site. Methods Mol Biol. 2014; 1150: 153-60.

PubMed Abstract |Publisher Full Text

54. Hochberg $Y$, Benjamini $Y$ : More powerful procedures for multiple significance testing. Stat Med. 1990; 9(7): 811-8. PubMed Abstract | Publisher Full Text

55. Rees CA, Demeter J, Matese JC, et al:: GeneXplorer: an interactive web application for microarray data visualization and analysis. BMC Bioinformatics. 2004; 5: 141. PubMed Abstract | Publisher Full Text | Free Full Text

56. Hollien J, Weissman JS: Decay of endoplasmic reticulum-localized mRNAs during the unfolded protein response. Science. 2006; 313(5783): 104-7. PubMed Abstract | Publisher Full Text

57. Arensdorf AM, Diedrichs D, Rutkowski DT: Regulation of the transcriptome by ER stress: non-canonical mechanisms and physiological consequences. Front Genet. 2013; 4: 256.

PubMed Abstract | Publisher Full Text | Free Full Text

58. Kaufman RJ: Orchestrating the unfolded protein response in health and 
disease. J Clin Invest. 2002; 110(10): 1389-98.

PubMed Abstract | Publisher Full Text | Free Full Text

59. Pahl HL: Signal transduction from the endoplasmic reticulum to the cell nucleus. Physiol Rev. 1999; 79(3): 683-701.

PubMed Abstract

60. Friedlander R, Jarosch E, Urban J, et al:: A regulatory link between ERassociated protein degradation and the unfolded-protein response. Nat $\mathrm{Cell}$ Biol. 2000; 2(7): 379-84.

PubMed Abstract | Publisher Full Text

61. Kalathur RK, Kamesh A, Futschik ME: The Unfolded Protein Response and its potential role in Huntington's disease. Nature Precedings. 2012.

Publisher Full Text

62. Möller T: Neuroinflammation in Huntington's disease. J Neural Transm (Vienna) 2010; 117(8): 1001-8.

PubMed Abstract | Publisher Full Text

63. Silvestroni A, Faull RL, Strand AD, et al.: Distinct neuroinflammatory profile in post-mortem human Huntington's disease. Neuroreport. 2009; 20(12): 1098-103. PubMed Abstract | Publisher Full Text

64. Dalrymple A, Wild EJ, Joubert R, et al:: Proteomic profiling of plasma in Huntington's disease reveals neuroinflammatory activation and biomarker candidates. J Proteome Res. 2007; 6(7): 2833-40. PubMed Abstract | Publisher Full Text

65. Singhrao SK, Neal JW, Morgan BP, et al.: Increased complement biosynthesis by microglia and complement activation on neurons in Huntington's disease. Exp Neurol. 1999; 159(2): 362-76. PubMed Abstract | Publisher Full Text

66. Sapp E, Kegel KB, Aronin N, et al:: Early and progressive accumulation of reactive microglia in the Huntington disease brain. $J$ Neuropathol Exp Neurol. 2001; 60(2): 161-72

PubMed Abstract | Publisher Full Text

67. Tai YF, Pavese N, Gerhard A, et al:: Microglial activation in presymptomatic Huntington's disease gene carriers. Brain. 2007; 130(Pt 7): 1759-66. PubMed Abstract | Publisher Full Text

68. Pavese N, Gerhard A, Tai YF, et al:: Microglial activation correlates with severity in Huntington disease: a clinical and PET study. Neurology. 2006; 66(11): 1638-43. PubMed Abstract | Publisher Full Text

69. Farrer LA: Diabetes mellitus in Huntington disease. Clin Genet. 1985; 27(1): 62-7. PubMed Abstract | Publisher Full Text

70. Podolsky S, Leopold NA: Abnormal glucose tolerance and arginine tolerance tests in Huntington's disease. Gerontology. 1977; 23(1): 55-63. PubMed Abstract | Publisher Full Text

71. Hurlbert MS, Zhou W, Wasmeier C, et al.: Mice transgenic for an expanded CAG repeat in the Huntington's disease gene develop diabetes. Diabetes. 1999; 48(3): 649-51.

PubMed Abstract | Publisher Full Text

72. Jenkins BG, Klivenyi $\mathrm{P}$, Kustermann $\mathrm{E}$, et al:: Nonlinear decrease over time in $\mathrm{N}$-acetyl aspartate levels in the absence of neuronal loss and increases in glutamine and glucose in transgenic Huntington's disease mice. $J$ Neurochem. 2000; 74(5): 2108-19.

PubMed Abstract | Publisher Full Text

73. Andreassen OA, Dedeoglu A, Stanojevic V, et al: Huntington's disease of the endocrine pancreas: insulin deficiency and diabetes mellitus due to impaired insulin gene expression. Neurobiol Dis. 2002; 11(3): 410-24. PubMed Abstract | Publisher Full Text

74. Stroedicke M, Bounab Y, Strempel N, et al:: Systematic interaction network filtering identifies CRMP1 as a novel suppressor of huntingtin misfolding and neurotoxicity. Genome Res. 2015; 25(5): 701-13. PubMed Abstract | Publisher Full Text | Free Full Text

75. Tam S, Geller R, Spiess C, et al:: The chaperonin TRiC controls polyglutamine aggregation and toxicity through subunit-specific interactions. Nat Cell Biol. 2006; 8(10): 1155-62.

PubMed Abstract | Publisher Full Text | Free Full Text
76. Lotz GP, Legleiter J, Aron R, et al:: Hsp70 and Hsp40 functionally interact with soluble mutant huntingtin oligomers in a classic ATP-dependent reaction cycle. J Biol Chem. 2010; 285(49): 38183-93.

PubMed Abstract | Publisher Full Text | Free Full Text

77. Min HJ, Ko EA, Wu J, et al:: Chaperone-like activity of high-mobility group box 1 protein and its role in reducing the formation of polyglutamine aggregates. $J$ Immunol. 2013; 190(4): 1797-806.

PubMed Abstract | Publisher Full Text | Free Full Text

78. Nishitoh H, Matsuzawa A, Tobiume K, et al:: ASK1 is essential for endoplasmic reticulum stress-induced neuronal cell death triggered by expanded polyglutamine repeats. Genes Dev. 2002; 16(11): 1345-55.

PubMed Abstract | Publisher Full Text | Free Full Text

79. Schmid JA, Birbach A: IkappaB kinase beta (IKKbeta/IKK2/IKBKB)--a key molecule in signaling to the transcription factor NF-kappaB. Cytokine Growth Factor Rev. 2008; 19(2): 157-65.

PubMed Abstract | Publisher Full Text

80. Frelin $\mathrm{C}$, Imbert $\mathrm{V}$, Griessinger $\mathrm{E}$, et al:: Targeting NF-kappaB activation via pharmacologic inhibition of IKK2-induced apoptosis of human acute myeloid leukemia cells. Blood. 2005; 105(2): 804-11.

PubMed Abstract | Publisher Full Text

81. Khoshnan A, Ko J, Tescu S, et al.: IKKalpha and IKKbeta regulation of DNA damage-induced cleavage of huntingtin. PLoS One. 2009; 4(6): e5768. PubMed Abstract | Publisher Full Text | Free Full Text

82. Muller-Rischart AK, Pilsl A, Beaudette $\mathrm{P}$, et al.: The E3 ligase parkin maintains mitochondrial integrity by increasing linear ubiquitination of NEMO. $\mathrm{Mol}$ Cell. 2013; 49(5): 908-21.

PubMed Abstract | Publisher Full Text

83. Jensen LT, Moller TH, Larsen SA, et al.: A new role for laminins as modulators of protein toxicity in Caenorhabditis elegans. Aging Cell. 2012; 11(1): 82-92. PubMed Abstract | Publisher Full Text | Free Full Text

84. Heng MY, Lin ST, Verret L, et al.: Lamin B1 mediates cell-autonomous neuropathology in a leukodystrophy mouse model. J Clin Invest. 2013; 123(6): 2719-29.

PubMed Abstract | Publisher Full Text | Free Full Text

85. Padiath QS, Saigoh K, Schiffmann R, et al:: Lamin B1 duplications cause autosomal dominant leukodystrophy. Nat Genet. 2006; 38(10): 1114-23. PubMed Abstract | Publisher Full Text

86. Giorgio $\mathrm{E}$, Robyr D, Spielmann $\mathrm{M}$, et al.: A large genomic deletion leads to enhancer adoption by the lamin B1 gene: a second path to autosomal dominant adult-onset demyelinating leukodystrophy (ADLD). Hum Mol Genet. 2015; 24(11): 3143-54

PubMed Abstract | Publisher Full Text | Free Full Text

87. Rué L, Alcalá-Vida R, López-Soop G, et al:: Early down-regulation of PKC $\delta$ as a pro-survival mechanism in Huntington's disease. Neuromolecular Med. 2014; 16(1): 25-37.

PubMed Abstract | Publisher Full Text

88. Naora $\mathrm{H}$, Takai I, Adachi M, et al:: Altered cellular responses by varying expression of a ribosomal protein gene: sequential coordination of enhancement and suppression of ribosomal protein S3a gene expression induces apoptosis. J Cell Biol. 1998; 141(3): 741-53. PubMed Abstract | Publisher Full Text | Free Full Text

89. Grupe A, Li Y, Rowland C, et al.: A scan of chromosome 10 identifies a novel locus showing strong association with late-onset Alzheimer disease. Am J Hum Genet. 2006; 78(1): 78-88.

PubMed Abstract | Publisher Full Text | Free Full Text

90. De Graeve S, Marinelli S, Stolz F, et al:: Mammalian ribosomal and chaperone protein RPS3A counteracts $\alpha$-synuclein aggregation and toxicity in a yeast model system. Biochem J. 2013; 455(3): 295-306. PubMed Abstract | Publisher Full Text | Free Full Text

91. Kalathur R, Giner-Lamia J, Machado S, et al.: Raw data for Kalathur et al., 2015 'The unfolded protein response and its potential role in Huntington's disease elucidated by a systems biology approach'. Figshare. 2015. Data Source 


\section{Open Peer Review}

\section{Current Peer Review Status:}

\section{Version 2}

Reviewer Report 03 March 2016

https://doi.org/10.5256/f1000research.8528.r9522

(C) 2016 Zeitlin S. This is an open access peer review report distributed under the terms of the Creative Commons Attribution License, which permits unrestricted use, distribution, and reproduction in any medium, provided the original work is properly cited.

\section{Scott Zeitlin}

Department of Neuroscience, School of Medicine, University of Virginia, Charlottesville, VA, USA

The authors' have added important data showing that changes in UPR gene expression strongly correlate with CAG repeat length.

Competing Interests: No competing interests were disclosed.

I confirm that I have read this submission and believe that I have an appropriate level of expertise to confirm that it is of an acceptable scientific standard.

\section{Version 1}

Reviewer Report 05 August 2015

\section{https://doi.org/10.5256/f1000research.6818.r9517}

(c) 2015 Taubert S. This is an open access peer review report distributed under the terms of the Creative Commons Attribution License, which permits unrestricted use, distribution, and reproduction in any medium, provided the original work is properly cited.

\section{Stefan Taubert}

Department of Medical Genetics, University of British Columbia, Vancouver, BC, Canada

In this paper, Kalathur et al. investigated the role of the ER's unfolded protein response (UPR) in the disease pathogenesis of Huntington's Disease (HD). Although HTT, the protein mutated in HD, does not localize to the ER, mutated HTT intereferes with downstream UPR processes, which may prevent the UPR from functioning normally and thus result in the induction of apoptosis by the UPR, which in turn could underlie the dramatic neuronal loss observed in HD. To broadly evaluate 
the role of UPR activation in the many experimental HD models and contexts, the authors used a bioinformatics approach to query for the role of the UPR in HD pathology, assessing transcriptomes, regulatory DNA elements, and UPR interactomes. The resulting data point to a core set of UPR genes that were commonly (although, as nicely pointed out, not universally) up- or downregulated in distinct experimental HD models, pro-inflammatory events involving microglia, a putative link between HD and diabetes/hyperglycemia, and the identification of a core set of genes that link UPR to apoptotic signaling and that $\mathrm{mHTT}$ may impinge upon.

Overall, this is a nice body of work. This computational analysis is comprehensive and multifaceted, the data interpretation measured and well-qualified, the paper well written, and the data are very accessible. One of the key strengths is that the authors aimed to integrate data obtained in many diferent experimental HD systems - various mouse models, human data, and even yeast and rat models. This comprehensive approach allows them to point to evolutionarily conserved genes and processes as suitable candidates for future investigation.

Specific criticism:

To derive their set of HTT interacting proteins, the authors use a dataset downloaded from HDNetDB database, which yields a large set of HTT interactors (HTT-int) including 1015 genes, including, as acknowledged, presumably many indirect interactors. Perhaps a deeper up-front curation for putative direct interactors would have been useful.

In Figure 2, the authors assess the overlap between genes regulated in 6 mouse HD datasets and one human HD. To ensure best stringency, the first limit the mouse dataset to those genes that are regulated in all 6 individual datasets. While this high stringency is laudable, one could have also lowered the stringency a bit in regards to inclusion in the core mouse IPR set, i.e. inclusion in 6/6 sets was deemed required, but expanding the set to 5/6 or even 4/6, resulting in 420 and 902 additional genes, respectively, would have only marginally lowered the stringency while providing a larger set for the determination of evolutionary conservation.

Competing Interests: No competing interests were disclosed.

\section{I confirm that I have read this submission and believe that I have an appropriate level of expertise to confirm that it is of an acceptable scientific standard.}

Author Response 17 Feb 2016

Ravi Kiran Reddy Kalathur, Centre for Biomedical Research, University of Algarve, Portugal

We thank the reviewer for the positive comments and specific suggestions that helped us to further improve our manuscript. In the revised version, we have included the additional analysis suggest by the reviewer.

1. We distinguish now between direct and indirect interactions of HTT based on their annotation in HDNetDB. An additional supplementary table (Supplementary dataset 8) presents now the classification of HTT interactions. This information was also used for the interpretation of our results. For instance, 2 of the 13 proteins constituting a putative link between HD and UPR, were direct interactors. We did not want to exclude a priori all indirect HTT interactors, since those might be part of larger 
protein complexes with HTT and thus potentially important for the HTT's molecular functions.

2. Additional lists of genes with evolutionary conserved expression were generated for less stringent filters (i.e. requiring the inclusion in the enrichment cores of at least 5 or 4 comparisons for up- or downregulated genes, respectively). In general, promotor and enrichment analyses of the extended gene lists agree well with those for the more stringent genes lists. The results are presented in supplementary tables and figures, and briefly discussed in the main manuscript. For the connection to HD, lowering the requirement led to detection of 53 candidates, of which 15 were direct HTT interactors (Supplementary figure 5). This enlarged set is presented in Supplementary dataset 9 for the interested reader.

Competing Interests: No competing interests were disclosed.

Reviewer Report 29 July 2015

https://doi.org/10.5256/f1000research.6818.r9713

(C) 2015 Zeitlin S. This is an open access peer review report distributed under the terms of the Creative Commons Attribution License, which permits unrestricted use, distribution, and reproduction in any medium, provided the original work is properly cited.

\section{Scott Zeitlin}

Department of Neuroscience, School of Medicine, University of Virginia, Charlottesville, VA, USA

In HD and other neurodegenerative disorders involving the accumulation of misfolded protein, ER stress and the activation of UPR have been implicated in pathogenesis, although the extent to which it contributes to neuronal cell death is still unclear. In this paper, the authors employ a bioinformatic approach to show that the unfolded protein response (UPR) is activated in a variety of human and animal Huntington's disease (HD) models. It is noteworthy that the authors also demonstrate that the upregulation of the UPR genes is most likely a direct response to UPR activation by analyzing the promoter regions of these genes for the binding sites of the UPR transcriptional activators ATF6 and XBP1. Moreover, the authors also identified sets of genes that provide a potential link between both UPR and HD and between UPR and apoptosis. Pathway enrichment analysis was also used to identify functional pathways activated by the common set of upregulated UPR genes. In addition to the expected pathways associated with UPR (e.g. PERKregulated gene expression and ATF-activated genes), the authors also identified components of the immune system, neurotrophin signaling, and diabetes. Interestingly, there is evidence in the HD literature that all three of these latter pathways are affected in HD.

This work is a good example of the power of using a systems biology approach to provide a fairly comprehensive analysis of UPR activation in HD. The authors are appropriately cautious in emphasizing that their results do not prove that the pathways and relationships between 
pathways that they have identified all contribute to HD pathogenesis. However, their results provide an excellent guide for further experimental studies, and the authors' development of a publicly accessible web site for the retrieval and visualization of their UPR-associated gene expression data in HD will be an important tool for the field that will facilitate these future studies.

Minor comments:

1. In the introduction, the authors mention that although HTT is not located in the ER, there are there are several potential mechanisms by which mutant HTT could induce ER stress (impairment of ERAD, dysfunctional vesicular trafficking, and altered ER calcium homeostasis). Atwal et al., (2007) and Atwal and Truant (2008) have shown that there is a more direct link between HTT and ER stress. In their work, they show that the N17 domain of HTT is a stress-sensitive ER association domain, and that the expanded polyQ stretch in mutant HTT perturbs the release of mutant HTT from ER and its translocation of HTT into and out of the nucleus in response to cell stress events.

2. p.7, $1^{\text {st }}$ paragraph: “...UPR has been also associated with the suppression or degradation of a substantial number of genes.... Do the authors mean: ...UPR has been also associated with the suppression or degradation of a substantial number of genes or gene products?

3. To account for the differences in differential UPR gene expression changes that were observed among the different HD mouse models, the authors suggest that differences in the $H T T$ transgenes and their expression levels among the models could be responsible. In addition, the different genetic backgrounds of the models can contribute to the variability. In future studies aimed at studying the role of the length of mutant HTT's expanded polyQ stretch in UPR activation, the authors may also want to consider evaluating CHDI's publicly available transcriptome data obtained from the cortex and striatum of 6-month old knock-in HD mouse models expressing wild-type or mutant $H t t$ alleles with different CAG repeat lengths.

Competing Interests: No competing interests were disclosed.

\section{I confirm that I have read this submission and believe that I have an appropriate level of expertise to confirm that it is of an acceptable scientific standard.}

Author Response 17 Feb 2016

Ravi Kiran Reddy Kalathur, Centre for Biomedical Research, University of Algarve, Portugal

We would like to thank the reviewer for the encouraging evaluating of our systems biology approach and his suggestions for further improvement of the study and its presentation. In response to the comments, following changes to the manuscript were made:

1. In the Introduction, we pointed out the finding of a stress-sensitive association of HTT with the ER membrane, which suggests a potential direct role of HTT in ER stress. The relevant references are now included.

2. We clarified the meaning of the sentence. It states now: "As the UPR has also been associated with suppression of gene transcription and the enhanced degradation of numerous transcripts, ..." 
3. We would like to thank reviewer for pointing out this data set. We analysed the correlation of expression changes with the length of polyglutamine tract. Notably, UPR genes were found to be strongly overrepresented among genes whose expression in the striatum significantly correlate with the length of polyglutamine tract. The correlation and the corresponding significance are also shown for the potential UPR-HD connectors in table 3 and Supplementary dataset 9. The results suggest length of the polyglutamine tract (which is reversely correlated with age of disease onset in human patients) plays a critical role in the activation of UPR. We aim to include these expression changes also in our newly developed web-portal UPRHD at http://uprhd.sysbiolab.eu.

Competing Interests: No competing interests were disclosed.

The benefits of publishing with F1000Research:

- Your article is published within days, with no editorial bias

- You can publish traditional articles, null/negative results, case reports, data notes and more

- The peer review process is transparent and collaborative

- Your article is indexed in PubMed after passing peer review

- Dedicated customer support at every stage

For pre-submission enquiries, contact research@f1000.com 